Open Access

\title{
Iron snow, crystal floats, and inner-core growth: modes of core solidification and implications for dynamos in terrestrial planets and moons
}

\author{
Doris Breuer ${ }^{*}$, Tina Rueckriemen and Tilman Spohn
}

\begin{abstract}
Recent planetary space missions, new experimental data, and advanced numerical techniques have helped to improve our understanding of the deep interiors of the terrestrial planets and moons. In the present review, we summarize recent insights into the state and composition of their iron (Fe)-rich cores, as well as recent findings about the magnetic field evolution of Mercury, the Moon, Mars, and Ganymede. Crystallizing processes in iron-rich cores that differ from the classical Earth case (i.e., Fe snow and iron sulfide (FeS) crystallization) have been identified and found to be important in the cores of terrestrial bodies. The Fe snow regime occurs at pressures lower than that in the Earth's core on the iron-rich side of the eutectic, where iron freezes first close to the core-mantle boundary rather than in the center. FeS crystallization, instead, occurs on the sulfur-rich side of the eutectic. Depending on the core temperature profile and the pressure range considered, FeS crystallizes either in the core center or close to the core-mantle boundary. The consequences of the various crystallizing mechanisms for core dynamics and magnetic field generation are discussed. For the Moon, revised paleomagnetic data obtained with advanced techniques suggest a peculiar history of its internal dynamo, with an early strong field persisting between 4.25 and $3.5 \mathrm{Ga}$, and subsequently a much weaker field. In addition, the long-lasting dynamo and the possible presence of an inner core, as inferred from a revised interpretation of Apollo seismic data, suggest core crystallization as a viable process of magnetic field generation for a substantial period during lunar evolution. The present-day magnetic fields of Mercury and Ganymede (if they occur on the iron-rich side of the Fe-FeS eutectic) and the related dynamo action are likely generated in the Fe snow regime and seem to be recent features. An earlier dynamo in Mercury would have been powered differently. For Mercury, MESSENGER data further suggest core formation under reducing conditions that may have resulted in an Fe-S-Si composition, further complicating the core crystallization process. Mars, with its early and strong paleo-field, likely has not yet started to freeze out an inner iron core.
\end{abstract}

Keywords: Core crystallization, Dynamo generation, Iron snow, Terrestrial planets, Thermal evolution

\section{Review} Introduction

Our view of the deep interiors of the terrestrial planets and moons, and their magnetic fields, has changed substantially over the past decade as a consequence of insights from recent space missions, new experimental data that have become available, and the results of more detailed and sophisticated numerical models. Because the evolution of a planet's magnetic field is closely linked

\footnotetext{
* Correspondence: doris.breuer@dlr.de

DLR, Institute of Planetary Research, Rutherfordstrasse 2, 12489 Berlin, Germany
}

to its thermal evolution, constraints on the dynamo in iron $(\mathrm{Fe})$-rich cores will help provide a better understanding of a planet's evolution in general. For instance, the MESSENGER mission has collected new magnetic field data for Mercury (e.g., Anderson et al. 2011; Johnson et al. 2015), and lunar samples have been reanalyzed with improved paleomagnetic methods (for a review, see Weiss and Tikoo 2014 among others). Space missions have further helped to better constrain the surface compositions of planets and to provide better constraints on geochemical models of their interiors. MESSENGER spectroscopic 
data show that the planet is more volatile rich than previously thought and additionally suggest that it was formed and differentiated under reducing conditions (Nittler et al. 2011; Weider et al. 2012). Therefore, the core is now thought to be composed of $\mathrm{Fe}-\mathrm{Si}-\mathrm{S}$ (e.g., Malavergne et al. 2010; Chabot et al. 2014) rather than Fe-S, which is generally taken as a good model for Earth-like planetary cores. Experimental data relevant to $\mathrm{Fe}-\mathrm{FeS}$ eutectic melting relations (Fei et al. 1997, 2000; Chudinovskikh and Boehler 2007; Stewart et al. 2007; Chen et al. 2008; Buono and Walker 2011) suggest that crystallization in the core can proceed substantially differently in small planets compared with the Earth's core. In small planets, iron may start crystallizing at the core-mantle boundary (CMB) rather than in the center, and iron snow may form (e.g., Hauck et al. 2006). As a consequence, a dynamo that is tied to crystallization may work differently in these planets than it would in Earth. Moreover, for a core richer in sulfur than the eutectic composition, iron sulfide $(\mathrm{FeS})$ will crystallize first and also result in a different crystallization process as compared with crystallization on the iron-rich side of the eutectic.

In the present paper, we review our present understanding of the composition, as well as the thermal and magnetic evolution, of the iron-rich cores of terrestrial planets and moons for which evidence of present or past magnetic fields is available. These are (in order of distance from the Sun) Mercury, the Moon, Mars, and Ganymede. Other planets, such as Venus, may have had magnetic fields. It has been speculated that Venus had a magnetic field driven by a thermal dynamo that vanished as the planet cooled (Stevenson et al. 1983; Gaidos et al. 2010), or it may have transited from plate tectonics to stagnant lid, losing its dynamo (Stevenson 2002). Another potential candidate for the presence of a magnetic field is the Jovian moon Io, although strong tidal heating may have prevented the formation of a dynamo (Wienbruch and Spohn 1995). This may also have been true for early Europa. It is likely that other large moons such as Callisto and Titan did not form an iron-rich core at all (e.g., Anderson et al. 2001; Iess et al. 2010). We begin by presenting the general concepts of thermal and compositional dynamos, along with a discussion of differences in crystallization at low and high pressures, and then proceed to discuss new findings and their implications for Mercury, the Moon, Mars, and Ganymede.

\section{Thermal and chemical dynamos}

Present-day magnetic fields of terrestrial planets and moons are either generated in their iron-rich cores (e.g., for the Earth, Mercury, and Ganymede), induced in electrically conducting layers (e.g., in the subsurface oceans of icy satellites), or are due to remanently magnetized crustal rock (e.g., for the Moon and Mars). The latter suggests a self-generated magnetic field during the early evolution of the planet, at the time of crustal formation. In any case, at the time of dynamo action, the presence of a convective (partially) fluid core is required, either an entirely fluid core or partially fluid with a solid inner core. We distinguish between thermal and chemical (compositional) dynamos.

For a fully fluid core, thermal buoyancy may be available to drive the dynamo if a sufficiently large superadiabatic temperature difference exists between core and mantle. The heat flux from the core needs to exceed the heat flux conducted along the core adiabat. The latter heat flux provides an important and necessary criterion for thermal convection in the core. The heat flux $\left(q_{\text {crit }}\right)$ along the adiabat is given by

$$
q_{\text {crit }}=\left.k_{c} \frac{\mathrm{d} T}{\mathrm{~d} r}\right|_{\mathrm{ad}}=\left.k_{c} \frac{\mathrm{d} T}{\mathrm{~d} P}\right|_{\mathrm{ad}} \frac{\mathrm{d} P}{\mathrm{~d} r}=k_{c} \frac{\alpha_{c} g_{c} T}{C_{p}}
$$

where $k_{c}$ is the thermal conductivity in the core, $\mathrm{d} T /$ $\left.\mathrm{d} r\right|_{\mathrm{ad}}$ the adiabatic temperature gradient, $P$ the pressure, $T$ the temperature, $r$ the radius, $\alpha_{c}$ the thermal expansivity, $C_{p}$ the heat capacity at constant pressure $p, g_{c}$ the gravity, and $\mathrm{d} T /\left.\mathrm{d} P\right|_{\mathrm{ad}}=\alpha_{c} T / \rho C_{p}$, with $\rho$ representing the density. Values for the critical heat flux that have been used in the literature vary between 5 and $20 \mathrm{~mW} \mathrm{~m}^{-2}$ for Mars (Nimmo and Stevenson 2000) and Mercury (Stevenson et al. 1983; Schubert et al. 1988) and between 1 and $10 \mathrm{~mW} \mathrm{~m}{ }^{-2}$ for the Moon (Zhang et al. 2013; Laneuville et al. 2014; Evans et al. 2014) and Ganymede (Hauck et al. 2006; Bland et al. 2008; Kimura et al. 2009; Rückriemen et al. 2015).

The large range of values for the critical heat flux originates mostly from uncertainties in the thermal conductivity and the thermal expansivity of the ironrich alloy at core pressures (Stacey and Anderson 2001). Recent ab initio calculations of transport properties suggest that the thermal conductivity in the Earth's core is a factor of two higher than previously thought, and thus upward revisions to the thermal conductivity in other terrestrial planets are also being discussed. Revised values of the thermal conductivity in the Earth's core range from 90 to $150 \mathrm{~W} \mathrm{~m}^{-1} \mathrm{~K}^{-1}$ (de Koker et al. 2012; Pozzo et al. 2012). Similar values also result from measurements of the electrical conductivity and from using the Wiedemann-Franz law to calculate the thermal conductivity (Gomi et al. 2013). Recently, Deng et al. (2013) suggested a thermal conductivity for Mercury's core of $113-125 \mathrm{~W} \mathrm{~m}^{-1} \mathrm{~K}^{-1}$ and a critical heat flux of $45-100 \mathrm{~mW} \mathrm{~m}^{-2}$ from measurements of the electrical conductivity of iron. Note, however, that ab initio calculations have recently been criticized by Zhang et al. (2015), who argued that such studies overestimate the thermal conductivity, because the effects 
of electron-electron scattering are not included in the numerical calculations.

The thermal conductivity likely decreases with increasing light-element abundances (e.g., Stacey and Anderson 2001; de Koker et al. 2012), although Ohta et al. (2015), using recent measurements of the electrical resistivity of iron-rich alloys, reported that the effect is not sufficiently large to reduce the core thermal conductivity to more conventional values of about $50 \mathrm{~W} \mathrm{~m}^{-1} \mathrm{~K}^{-1}$ (Stacey and Anderson 2001). For the discussion in this paper, we emphasize the implications of larger values for the thermal conductivity, although we note, of course, that the matter is not yet entirely settled.

The thermal expansivity of liquid iron at ambient pressure ranges from $8.2 \times 10^{-5} \mathrm{~K}^{-1}$ to $13.2 \times 10^{-5} \mathrm{~K}^{-1}$ (Hixson et al. 1990; Nasch and Steinemann 1995; Assael et al. 2006). The expansivity also depends slightly on the volatile content (Kaiura and Toguri 1979). With increasing pressure the thermal expansivity decreases, and a value of about $10^{-5} \mathrm{~K}^{-1}$ to $3 \times 10^{-5} \mathrm{~K}^{-1}$ is proposed for the Earth's core (Boehler et al. 1990; Kandpal and Gupta 2007).

It is important to note that the heat flux from the core is controlled mainly by the thermal evolution of the overlying mantle. The mantle needs to remove heat from the core at a rate that exceeds the critical heat flow for the core to become convective. If the mantle removes heat at a rate below the critical heat flow, the core will be stratified thermally stably, cooling conductively, and dynamo action driven by thermal convection is not possible.

Compositional convection can occur when a buoyant chemical component is released during the freezing of a fluid core with a non-eutectic composition (Braginsky 1964). The existence of light alloying elements in the core is cosmochemically reasonable and has been postulated for all terrestrial planets and moons, but the nature and the concentrations of the suggested light elements vary, as we discuss below. In any case, these elements will, other than reducing the average core density, significantly reduce the melting temperature of the core alloy (e.g., Usselman 1975; Fei et al. 1997). Although the effects of a variety of elements are conceivable, the physics of crystallization in the core has been studied mostly for Fe-FeS systems, both experimentally and theoretically.

\section{Core crystallization processes}

Recent experimental work has shown that the rate of change of the eutectic temperature $T_{e}$ with pressure for $\mathrm{Fe}-\mathrm{FeS}$ will change sign at a pressure of $14 \mathrm{GPa}$ : it is negative for lower pressures and positive otherwise (e.g., Fei et al. 1997, 2000; Chudinovskikh and Boehler 2007; Stewart et al. 2007; Chen et al. 2008; Buono and Walker 2011). As a consequence, crystallization in a cooling core will proceed very differently in a large planet, where the pressure is significantly higher than $\sim 40 \mathrm{GPa}$, compared with a small planet where the pressure is lower. While the former case is applicable to the Earth's core, the latter is applicable to Mars as well as to smaller planets and moons (see Table 1). The case of the Earth's core has been studied extensively in past decades, while the smaller planets are the subjects of ongoing research.

\section{Inner-core growth}

The conventional model of inner-core growth on the Ferich side of the eutectic is applicable to cases where the (positive) slope of the core liquidus is steeper than that of the adiabat, $\mathrm{d} T / \mathrm{d} P_{\text {melt }}>\mathrm{d} T / \mathrm{d} P_{\text {ad }}$ (e.g., Stevenson et al. 1983; see Fig. 1a). As a consequence, when the core has cooled sufficiently to reach the liquidus at the center, iron will crystallize and an inner-core nucleus will form; upon further cooling, the core will freeze from the inside out.

Table 1 Parameters of the interior structure

\begin{tabular}{|c|c|c|c|c|c|}
\hline & Earth & Moon & Mercury & Mars & Ganymede \\
\hline Planetary radius $(\mathrm{km})$ & $6371^{a}$ & $1737^{b}$ & $2439^{c}$ & $3389^{\text {d,e }}$ & $2632^{f}$ \\
\hline Surface gravity $\left(\mathrm{m} \mathrm{s}^{-2}\right)$ & $9.8^{\mathrm{a}}$ & $1.6^{\mathrm{a}}$ & $3.7^{\mathrm{a}}$ & $3.7^{\mathrm{a}}$ & $1.4^{\mathrm{a}}$ \\
\hline Core radius (km) & $2890^{a}$ & $250-430^{b}$ & $1965-2050^{g, h}$ & $1370-1870^{\mathrm{d}, \mathrm{e}}$ & $650-880^{f}$ \\
\hline$R_{C} / R_{p}$ & $0.45^{a}$ & $0.14-0.25^{b}$ & $0.8-0.84^{\mathrm{g}, \mathrm{h}}$ & $0.4-0.55^{\mathrm{d}, \mathrm{e}}$ & $0.25-0.33^{f}$ \\
\hline$P_{\mathrm{cm}}(\mathrm{GPa})$ & $139^{a}$ & $4.5-5^{i}$ & $2.8-3.3^{h}$ & $20-25^{d, e}$ & $5.5-7^{f}$ \\
\hline$P_{c}(\mathrm{GPa})$ & $357^{a}$ & $5-6^{i}$ & $33-37^{h}$ & $38-42^{\text {d,e }}$ & $9.5-11^{f}$ \\
\hline Gravity at CMB $\left(\mathrm{m} \mathrm{s}^{-2}\right)$ & $10.3^{a}$ & $0.7^{b}$ & $4^{h}$ & $3^{d, e}$ & $1.3^{f}$ \\
\hline
\end{tabular}

Parameters of the interior structure for the Moon, Mercury, Mars, and Ganymede. Earth is included for comparison

$R_{\mathrm{c}} / R_{\mathrm{p}}$ is the relative core radius, $P_{\mathrm{cm}}$ is the density at the core-mantle boundary, $P_{\mathrm{c}}$ is the central pressure

aLodders and Fegley (1998)

${ }^{\mathrm{b}}$ Sohl and Schubert (2007)

${ }^{c}$ Anderson et al. (1987)

${ }^{\mathrm{d} S o h l}$ and Spohn (1997)

esohl et al. (2005)

fSohl et al. (2002)

${ }^{g}$ Hauck et al. (2013)

${ }^{h}$ Rivoldini and Van Hoolst (2013)

iSohl et al. (2009) 
a

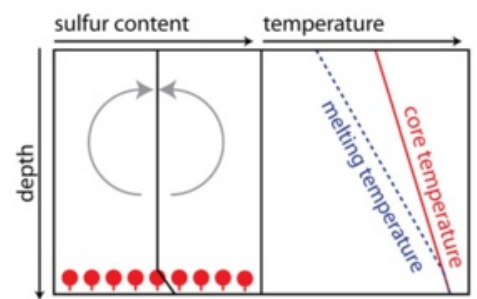

b

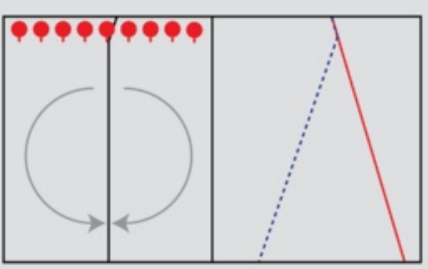

C

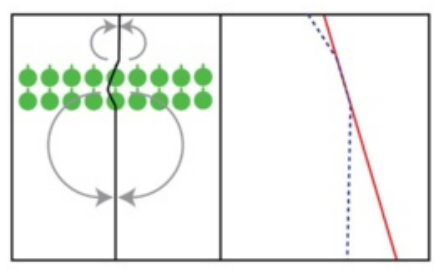

d

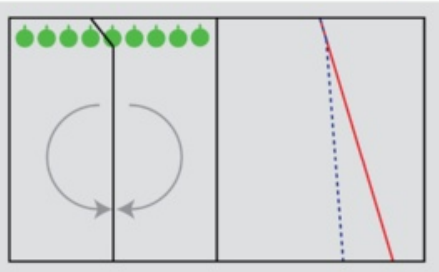

e

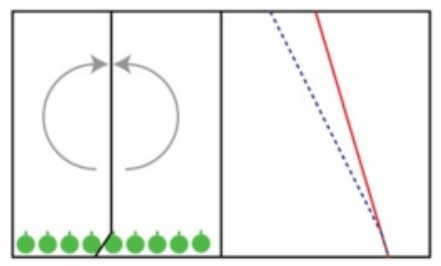

f

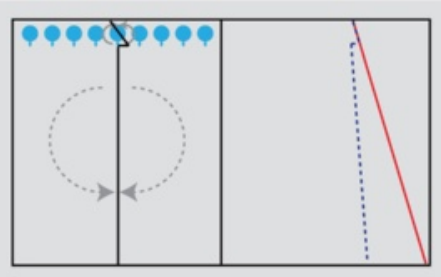

g

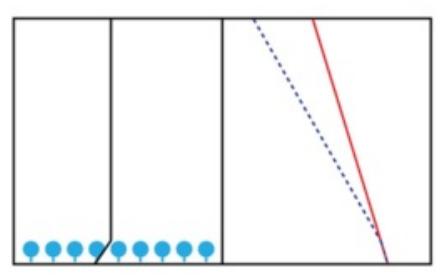

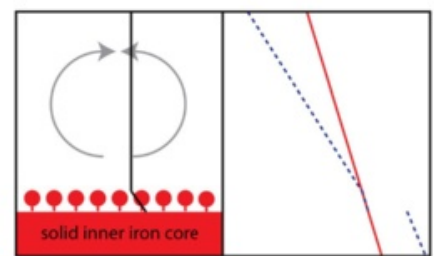
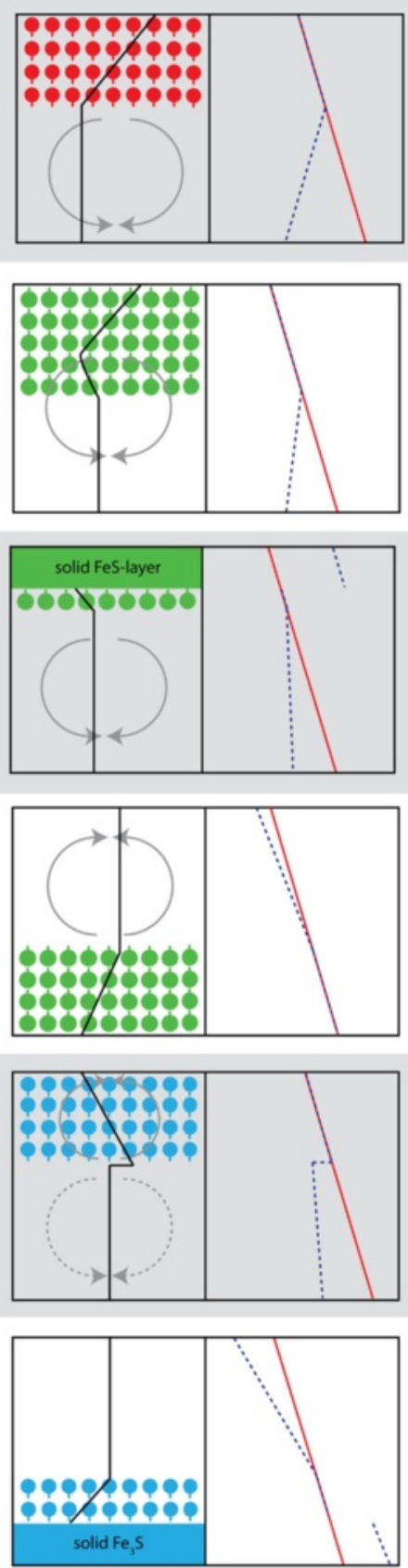
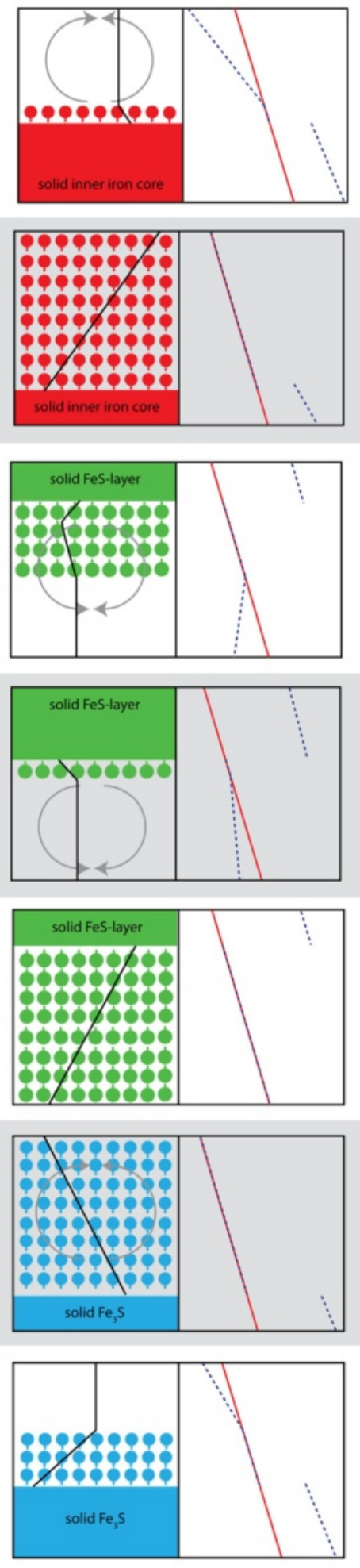

time

Fig. 1 (See legend on next page.) 
(See figure on previous page.)

Fig. 1 Crystallization scenarios in the Fe-FeS system. Crystallization scenarios in the Fe-FeS system. a Earth-like, Fe-rich inner core grows from the center. Sulfur is enriched in the outer core and drives chemical convection. $\mathbf{b}$ Iron snow forms at the CMB, sinks, and remelts at depth and drives chemical convection. The stable snow zone grows in time. When it reaches the center, an inner solid core will form. c Floating FeS crystals form a stable zone growing toward the CMB where eventually a solid FeS layer will form. The fluid below is enriched in iron and unstable to convection. $\mathbf{d}$ A solid FeS layer grows from the CMB. Expulsion of Fe results in chemical convection in the fluid below as in (c). e FeS crystals rise from the center and remelt at lower depths. The liquid above the FeS zone is convectively unstable. When the FeS crystal zone reaches the $\mathrm{CMB}$, a solid FeS layer will form. f Fe $3 \mathrm{~S}$ snow forms at the $\mathrm{CMB}$ and the chemically unstable snow zone grows until it comprises the entire core where a solid $\mathrm{Fe}_{3} \mathrm{~S}$ inner core will form. The layer below is chemically homogeneous but may convect thermally. $\mathbf{g} \mathrm{A}$ solid $\mathrm{Fe}_{3} \mathrm{~S}$ inner core grows with time without the release of chemical buoyancy to the outer core and convection above. Red, green, and blue dots indicate solid iron, solid $\mathrm{FeS}$, and $\mathrm{Fe}_{3} \mathrm{~S}$, respectively. Short dashes show the direction of sinking or rising. Red solid lines are the core temperature, blue dashed lines the core melting temperature, and black solid lines the concentration of sulfur, respectively. Solid arrows indicate chemical and dashed arrows thermal convection, respectively. For further explanation, see text

The outer core will be increasingly depleted in iron and enriched in sulfur until the eutectic composition is reached. At that point, the core will continue to freeze in a eutectic composition. Figure 2 shows, for various initial sulfur concentrations, the enrichment of sulfur in the outer fluid core and the associated inner-core size, assuming that the inner solid core is free of sulfur. The maximum relative inner-core size, which is attained when the outer core has a eutectic composition, decreases with increasing initial sulfur concentration.

During crystallization, the concentration of sulfur will not be homogeneous; instead, a boundary layer will form just above the inner core, where the sulfur concentration is above average. The fluid in this layer will be lighter than in the remainder of the fluid core, and compositional convection will be induced to homogenize the outer-core composition. Chemical convection and the associated generation of a magnetic field in the core will occur if the temperature in the fluid (outer) core lies between that of the solidus and the liquidus of the core alloy. Inner-core growth will induce outer-core convection even if the heat flow through the CMB is lower than the critical heat flow for a thermal dynamo, as discussed above (e.g., Stevenson et al. 1983). Thus, the temperature gradient may be even shallower than adiabatic, and compositional convection may carry heat downward, against the temperature gradient. The buoyancy release associated with this compositional change exceeds the work done against the stabilizing thermal stratification.

\section{Iron snow regime}

Compositional convection, however, can be very different from the scenario described above in smaller planetary bodies or for higher sulfur contents than characteristic of the eutectic composition. Recent experimental studies (e.g.,

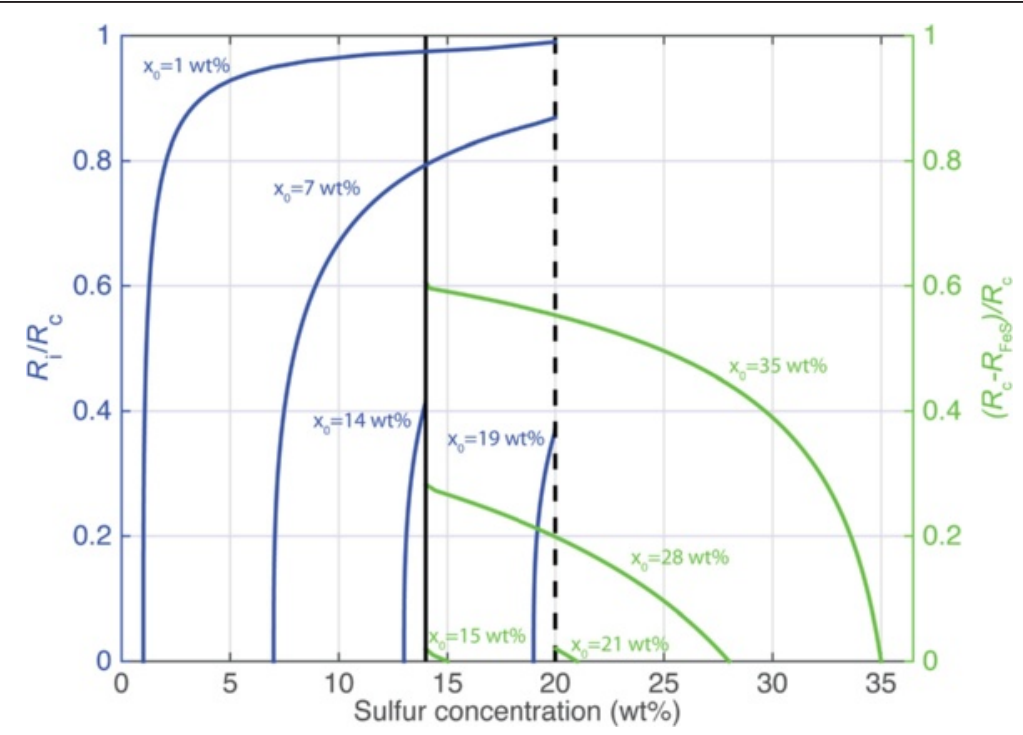

Fig. 2 Radius of solid inner Fe core and thickness of solid FeS layer. Relative radius of the solid inner Fe core (blue lines) and thickness of the solid FeS layer (green lines) as a function of the sulfur content in the fluid part of the core and depending on the initial sulfur content. $R_{i}$ is the innercore radius, $R_{C}$ the core radius, and $R_{\text {Fes }}$ the radius of the lower boundary to the solid FeS layer. Shown are initial sulfur concentrations of 1, 7, 14, 15, 19, 21,28 , and $35 \mathrm{wt} . \%$. The solid and dashed vertical lines indicate the eutectic sulfur concentration at different pressures (14 wt.\% corresponds to $\sim 30 \mathrm{GPa}$ and 20 wt.\% to $\sim 10 \mathrm{GPa}$ ). Left of the eutectic a solid inner Fe core and right of the eutectic a solid FeS layer are formed. The relative inner-core radius and Fes layer thickness are smaller the closer the sulfur content is to the eutectic 
Fei et al. 1997, 2000; Li et al. 2001; Chudinovskikh and Boehler 2007; Stewart et al. 2007; Chen et al. 2008; Buono and Walker 2011) have revealed two important aspects of the Fe-FeS phase diagram: (1) at pressures below 14 GPa, the eutectic melting temperature decreases with increasing pressure; and (2) the $S$ content at the eutectic decreases with increasing pressure up to a pressure of $60 \mathrm{GPa}$ (Stewart et al. 2007; Chudinovskikh and Boehler 2007; Morard et al. 2008; Figs. 3 and 4). Note that the exact decline of the eutectic concentration with pressure is somewhat uncertain. While Fei et al. (1997, 2000) found that the eutectic concentration remains constant between $\sim 7$ and $10 \mathrm{GPa}$, the data of Morard et al. (2007) suggest a constant eutectic concentration between slightly higher pressures of $\sim 11$ and $15 \mathrm{GPa}$ (see Fig. 5 in Morard et al. 2007). These uncertainties also impact the slope of the melting temperature, which is typically obtained through linear interpolation of the melting temperature of the endmembers ( $\mathrm{Fe}-\mathrm{FeS}$ eutectic and pure Fe or pure $\mathrm{FeS}$ ).

A melting temperature profile with a negative slope (or a shallower melting temperature profile than that of the core temperature, $\left.\mathrm{d} T / \mathrm{d} P_{\text {melt }}<\mathrm{d} T / \mathrm{d} P_{\text {ad }}\right)$ will have profound implications. Upon cooling, Fe will precipitate at the CMB rather than in the center and may fall as iron snow, since the solid iron particles are heavier than the surrounding $\mathrm{Fe}-$ FeS fluid (Fig. 1b). A snow zone forms, limited from below, at a depth where the core temperature is higher than the melting temperature, and the iron snow particles remelt. Owing to the solidification of iron, the concentration of sulfur increases in the snow zone, and the liquidus of the fluid decreases there (e.g., Buono and Walker 2011). Under the assumption of thermodynamic equilibrium, iron continues to solidify and the local sulfur concentration in the liquid increases until the liquidus reaches the core temperature. Thus, in the snow zone, the liquidus becomes collinear with the core temperature and reverses its slope, so that the liquidus temperature increases with increasing depth. The increase of the liquidus with depth in the snow zone is inevitably accompanied by a decrease in the sulfur concentration with depth, which implies the presence of a stable chemical gradient across the snow zone (Hauck et al. 2006; Williams 2009; Rückriemen et al. 2015).

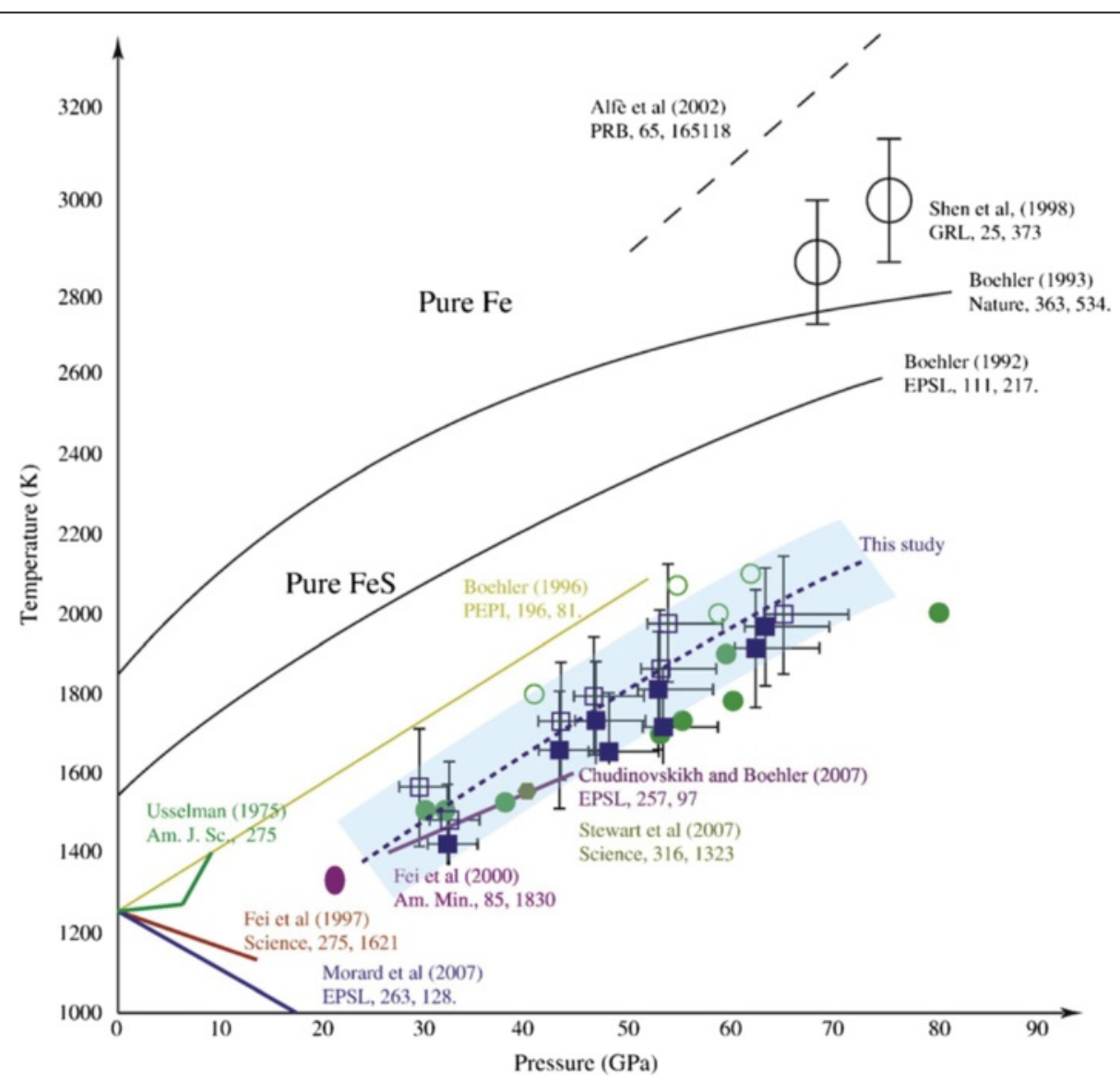

Fig. 3 Pressure dependence of the eutectic temperature in the Fe-FeS system. Pressure dependence of the eutectic temperature in the Fe-FeS system. Empty squares indicate the presence of melt, while filled squares indicate the presence of $\mathrm{Fe}$ and $\mathrm{Fe}_{3} \mathrm{~S}$ solid phases only. The solid line represents linear interpolation for this data set. Other melting data are from Usselman (1975), Boehler (1993), Boehler (1996), Fei et al. (1997, 2000), Shen et al. (1998), Alfè et al. (2002b), Campbell et al. (2007), Chudinovskikh and Boehler (2007), Morard et al. (2007), and Stewart et al. (2007). Figure after Morard et al. (2008) 


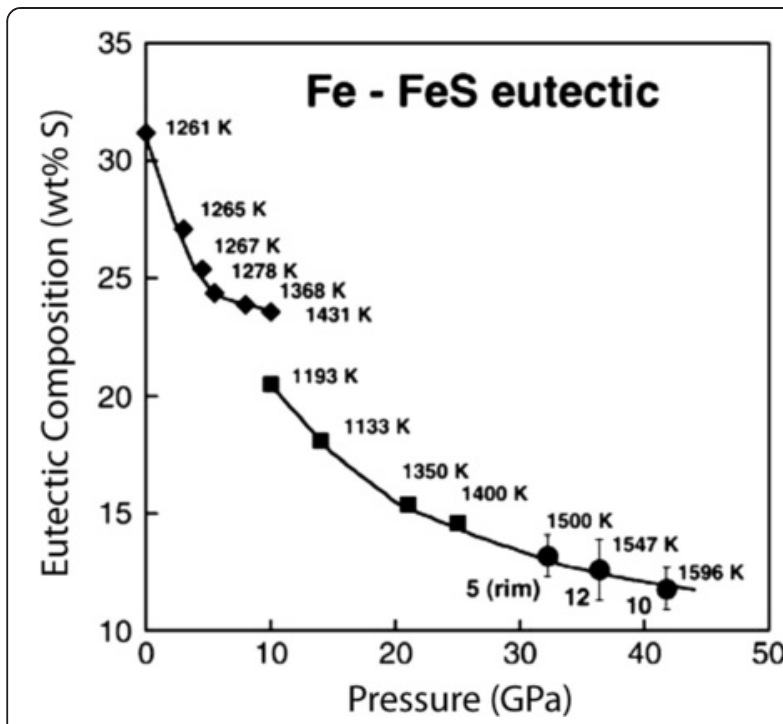

Fig. 4 Pressure dependence of Fe-FeS eutectic composition. Pressure dependence of the Fe-FeS eutectic composition (wt.\% S); circles: Chudinovskikh and Boehler (2007); diamonds: Usselman (1975); squares: Fei et al. (1997, 2000) and Li et al. (2001). Figure after Chudinovskikh and Boehler (2007). The eutectic melting temperature is also given

The remelting of iron particles below the snow zone results in a local enrichment of iron in the Fe-FeS melt. This creates a gravitationally unstable situation, where a heavier layer is formed on top of a lighter one. The Ferich layer initiates compositional overturn, which leads to a well-mixed state of the deeper, entirely liquid core below the snow zone. With ongoing cooling, the snow zone grows at the expense of the deeper, well-mixed fluid core. Finally, an inner core begins to grow when the snow zone encompasses the entire core, because the sinking iron particles can no longer remelt.

This so-called iron snow regime has already been suggested to apply to the present cores of Ganymede (Hauck et al. 2006; Christensen 2015; Rückriemen et al. 2015) and Mercury (Chen et al. 2008; Vilim et al. 2010; Wicht and Heyner 2014). It has also been suggested that Mars' core may enter the iron snow regime (Stewart et al. 2007) and that the lunar core may have gone through an iron snow episode (Zhang et al. 2013; Laneuville et al. 2014). Although the thermodynamics of the iron snow regime seems to be reasonably well developed, the questions of how and where a magnetic field can be generated in an iron snow core remain debated. Hauck et al. (2006) suggested that the power dissipated by the sinking iron snow zone is sufficient to drive a dynamo. Their work is supported by that of Zhan and Schubert (2012), who obtained a multipolar magnetic field using a magneto-hydrodynamic model where the fluid motions within the snow zone resembled internally heated convection. In contrast to these studies, Bland et al. (2008) argued that compositionaldriven convection in the Fe snow zone would not provide enough power to generate a magnetic field, since the latent heat is released close to the CMB and cannot be used to efficiently drive the dynamo. In
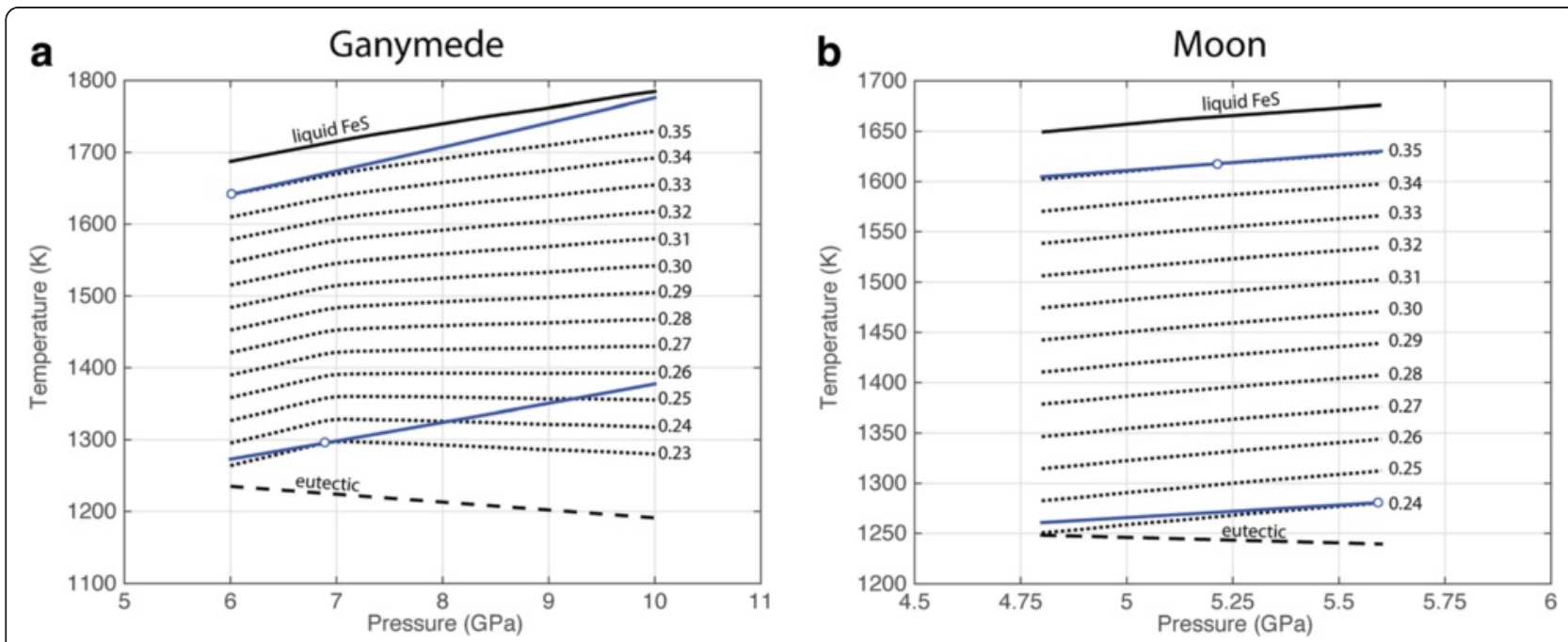

Fig. 5 Melting temperature on the sulfur-rich side of eutectic. Melting temperature of FeS (solid black line) and Fe-FeS eutectic (dashed black line) as a function of pressure. FeS data are from Boehler (1992) and Fe-FeS eutectic from Fei et al. (1997, 2000). Dotted lines are melting temperatures for different sulfur contents, obtained by linear interpolation between the melting temperatures of FeS and Fe-FeS eutectic. a corresponds to the pressure range of Ganymede's core and (b) corresponds to the pressure range of the Moon's core. Blue solid lines correspond to adiabatic temperature profiles and white circles indicate the point where melting and core temperatures coincide first during cooling, i.e., where crystallization of FeS starts. The adiabatic temperature profiles have been calculated for $a=9 \times 10^{-5} \mathrm{~K}^{-1}, \rho=5500 \mathrm{~kg} \mathrm{~m}{ }^{-3}, \mathrm{cp}=830 \mathrm{~J} \mathrm{~kg}$, $g=1 \mathrm{~m} \mathrm{~s}^{-2}$ (Ganymede), and $a=9 \times 10^{-5} \mathrm{~K}^{-1}, \rho=5500 \mathrm{~kg} \mathrm{~m}^{-3}, \mathrm{cp}=830 \mathrm{~J} \mathrm{~kg} \mathrm{~kg}^{-1}, g=0.6 \mathrm{~m} \mathrm{~s}$ (Moon). Depending on the sulfur content, for Ganymede, FeS starts to crystallize in the core or at the CMB and for the Moon, FeS starts to crystallize in the core or in the core center 
addition, Rückriemen et al. (2015) argued that the nature of the convection induced by sedimentation in an otherwise chemically stably stratified layer is likely of small scale and thus lacks an important criterion (i.e., large-scale convection) that is necessary for dynamo action (Christensen and Wicht 2007). Instead, it is argued that the dynamo may be located in the iron-rich layer below the snow zone. Here, vigorous convection caused by the release of buoyancy upon remelting of iron may drive the dynamo (Vilim et al. 2010; Christensen 2015; Rückriemen et al. 2015). However, this dynamo would only be active during the period between the formation of the snow zone and the time when it reached the center of the core.

Most dynamo models for iron snow cores have thus far been calculated for Ganymede, and these will be discussed in more detail in the section about Ganymede below. Note, however, that the iron snow scenario described above assumes thermodynamic equilibrium. It might also be possible that the iron particles sink so rapidly that they fail to remelt (completely) before reaching the center. Whether or not a dynamo may then still be possible remains an open question.

\section{Precipitation of FeS}

If the core is sulfur rich (i.e., if its sulfur content is greater than the eutectic concentration), solid $\mathrm{FeS}$ (or $\mathrm{Fe}_{3} \mathrm{~S}_{2}$ for pressures between 14 and $20 \mathrm{GPa}$, and $\mathrm{Fe}_{3} \mathrm{~S}$ for even higher pressures) will precipitate within the core (Fei et al. 2000; Hauck et al. 2006; Campbell et al. 2007; Stewart et al. 2007; Morard et al. 2008). Figure 5 shows the melting temperature as a function of pressure for various sulfur concentrations, assuming a linear interpolation of the melting temperature between pure $\mathrm{FeS}$ and the eutectic melting temperature. The pressure ranges shown represent conditions in Ganymede and the Moon. For Ganymede (Fig. 5a), a comparison with the adiabatic temperature profile shows that for concentrations close to the eutectic, freezing will start at about $7 \mathrm{GPa}$; i.e., within the core but close to the CMB. Because of the high sulfur content of FeS ( 36.5 wt.\% S), even solid FeS will be less dense than the residual liquid, provided that the composition of the liquid is not close to FeS. The increasing concentration of solid FeS will remelt at shallower depths, thus increasing the $\mathrm{S}$ concentration and the liquidus temperature there (on the sulfur-rich side of the eutectic, the melting temperature increases with the sulfur content; see Fig. 1c). Over time, a layer forms where solid FeS rises (FeS floating zone) and where the temperature is equal to the melting temperature. The floating zone can be divided into two parts. The upper part, where $\mathrm{d} T / \mathrm{d} P_{\text {melt }}>\mathrm{d} T / \mathrm{d} P_{\text {ad }}$, exhibits a chemically stable gradient, and the lower part, where $\mathrm{d} T /$ $\mathrm{d} P_{\text {melt }}<\mathrm{d} T / \mathrm{d} P_{\text {ad }}$, is chemically unstable, including the fluid layer below. The fluid of the lower floating zone is left enriched in iron and tends to remix with the deeper fluid core, leading to a decrease in the melting temperature there. The floating zone grows toward the CMB until an FeS layer forms at the CMB. The subsequent crystallization of the core proceeds similarly to the growth of the Earth's inner core but in reverse as the solid FeS layer grows in thickness toward the center. The continuous enrichment of Fe in the fluid inner core will maintain chemical convection and may drive a dynamo.

For sulfur concentrations greater than about $31 \mathrm{wt} . \%$, crystallization of FeS will start immediately at the $\mathrm{CMB}$ and an FeS layer will grow in time from there (see Fig. 1d). This is similar to the scenario shown in Fig. 1c when the floating zone has reached the CMB. Figure 2 (right-hand side) shows the depletion of sulfur in the fluid inner core as a consequence of the growth of the FeS layer for various initial sulfur concentrations. The FeS outer core will grow in thickness until the eutectic composition is reached in the inner core. From that point in time, the core will freeze in eutectic composition. The maximum thickness of the FeS outer core, expressed in core radii, decreases with decreasing initial sulfur concentration. Hauck et al. (2006) argue that FeS crystallization will start in the center of Ganymede (rather than in the upper core, as argued above). This is possible, but it requires a conductive core with a suitably small temperature gradient at the onset of freezing (see Fig. 5a).

For the Moon, we do indeed find that FeS would start crystallizing at the center of the core. In this case, an FeS floating zone develops with a stable chemical gradient where FeS crystallizes and rises upward toward the outer core (see Fig. 1e), just like in an inverted iron snow scenario. When FeS remelts, it releases buoyancy, which may drive chemical convection in the outer core. With core cooling, the FeS floating zone grows toward the $\mathrm{CMB}$. When this zone eventually comprises the entire core, solid FeS remelting will cease and a solid FeS layer begins to grow at the CMB. This scenario results in dynamics similar to that of the iron snow regime on the Fe-rich side of the eutectic, although the direction of growth of the floating zone is reversed, with solid particles rising instead of sinking. There may thus be a dynamo in the fluid outer core above the floating zone rather than one in a fluid inner core below the iron snow zone. The dynamo would be active as long as the floating zone grows.

For core pressures higher than about $21 \mathrm{GPa}$, solid $\mathrm{Fe}_{3} \mathrm{~S}$ forms for S contents higher than the eutectic (Fei et al. 2000; Campbell et al. 2007; Stewart et al. 2007; Morard et al. 2008). The slope of the eutectic temperature is estimated at $15 \mathrm{~K} \mathrm{GPa}^{-1}$ (Campbell et al. 2007; Morard et al. 2008). For Mars, precipitation of $\mathrm{Fe}_{3} \mathrm{~S}$ would first occur at the CMB, because $\mathrm{d} T / \mathrm{d} P_{\text {melt }}<\mathrm{d} T / \mathrm{d} P_{\text {ad }}$ is given for most plausible parameter variations to determine the adiabatic 
temperature profile. $\mathrm{Fe}_{3} \mathrm{~S}$ is denser than the residual liquid (Stewart et al. 2007), so it sinks into the core and remelts where $T_{c}>T_{\text {melt }}$ (Fig. 1f). The crystallization process of $\mathrm{Fe}_{3} \mathrm{~S}$ is similar to that in the iron snow regime (Fig. 1b), because an $\mathrm{Fe}_{3} \mathrm{~S}$ snow region forms at the CMB. However, there are important differences. The density profile of the liquid in the $\mathrm{Fe}_{3} \mathrm{~S}$ snow region is unstable. The sinking and remelting of $\mathrm{Fe}_{3} \mathrm{~S}$ results in an increase in $\mathrm{S}$ with increasing depth, which results in turn in a decreasing density with depth. In the $\mathrm{Fe}_{3} \mathrm{~S}$ snow region, therefore, the material continuously crystallizes and remelts because of this unstable situation. Below the snow zone, compositional convection is absent, since the remelting of $\mathrm{Fe}_{3} \mathrm{~S}$ results in a local increase of $\mathrm{S}$ and leads to the formation of a lower density fluid layer on top of the denser liquid core below. This situation is stable. However, thermally driven convection in the bottom fluid layer may still be possible, since the heat flow from the lower core is adiabatic owing to the convective snow zone. Over time, the $\mathrm{Fe}_{3} \mathrm{~S}$ snow region comprises the entire core and a solid inner $\mathrm{Fe}_{3} \mathrm{~S}$ core forms. For this crystallization scenario, we can find two convection layers and, therefore, two dynamo regions if thermally driven convection is efficient in the liquid inner core. Alternatively, the dynamo region is located in the upper core, attains its maximum extent when the snow zone reaches the center, and then shrinks again owing to the growth of the solid inner core.

If $\mathrm{Fe}_{3} \mathrm{~S}$ crystallizes first in the core center (see Fig. 1g), which is possible for a conductive temperature profile, the dense crystals remain in the center to form an inner core, as in the conventional Earth scenario. Compositional convection in the outer liquid core is unlikely to occur, since the liquid from which $\mathrm{Fe}_{3} \mathrm{~S}$ crystallizes will be depleted in $\mathrm{S}$ and its density will increase. A fluid layer forming in the solid $\mathrm{Fe}_{3} \mathrm{~S}$ core, which is denser than the remaining fluid core, does not induce an upward flow through compositional buoyancy forces, and dynamo action is less efficient or even unlikely.

\section{Scaling laws and power for dynamo action}

Scaling laws have been derived in recent years for hydromagnetic dynamos which relate magnetic induction to the buoyancy flux, a measure of the convective power available for the dynamo, and the dimensions of the dynamo region (e.g., Christensen and Tilgner 2004; Christensen and Aubert 2006; Olson and Christensen 2006; Aubert et al. 2009). These scaling laws suggest that the magnetic field strength is related to the convective power available to balance ohmic dissipation and that it is not determined by a force balance between the Coriolis and Lorentz forces, as in the older scaling laws (e.g., Busse 1976; Stevenson 1979; Curtis and Ness 1986). A scaling based on ohmic dissipation has already been used by
Stevenson et al. (1983). A detailed discussion of the various scaling laws can be found in Christensen (2010).

The scaling laws derived from dynamo simulations are characterized by diffusivities and viscosities that are many orders of magnitude too large. Such large values are chosen to dampen any small-scale flow that cannot be resolved with the present numerical resolution and available computational power. The scaling of Christensen and Aubert (2006) attempts to circumvent this problem by avoiding diffusivity and viscosity. While a weak dependence on the magnetic Prandtl number leads to a slightly better fit to the simulated data (e.g., Christensen 2010), the main advantage of the present scaling is that it satisfactorily covers a wide range of parameters, from planetary dynamos to dynamos of fully convective rapidly rotating stars. Future simulations for more extreme parameters than those explored by Christensen and Aubert (2006) will further clarify the applicability of the proposed scaling law.

Accordingly, the surface value of the magnetic induction can be calculated using

$$
B_{\text {surf }}=f \mu_{0}^{1 / 2} \rho_{c}{ }^{1 / 6}(\phi D)^{1 / 3}\left(\frac{R_{c}}{R_{p}}\right)^{3}
$$

where $f$ is a constant prefactor that includes the partitioning of energy between the poloidal and toroidal components, $\mu_{0}$ is the permeability of free space, $\rho_{c}$ the core density, $\phi$ the volumetric ohmic dissipation rate, $D$ the thickness of the fluid core, $R_{c}$ the core radius, and $R_{p}$ the planetary radius. The final term shows that the decrease of the field strength is proportional to at least the third power of the distance to the surface.

To calculate the ohmic dissipation rate, an entropy balance is required for the core. Ohmic and viscous dissipation do not enter the core's global energy budget, but, as irreversible processes, both are sources of entropy. In the fluid regions of the core, viscous dissipation can be neglected compared with ohmic dissipation. The entropy budget for the core (for a review, see Nimmo 2007) reads

$$
E_{\Phi}=E_{S}+E_{g}+E_{L}+E_{\mathrm{rad}}-E_{\mathrm{ad}}
$$

where $E_{\Phi}$ is the rate of entropy production through ohmic dissipation, $E_{S}$ is the entropy production rate owing to secular cooling, and $E_{g}$ owing to the release of chemical buoyancy. $E_{L}, E_{\mathrm{rad}}$, and $E_{\mathrm{ad}}$ are the entropy production rates owing to latent heat release, radioactive heating, and conduction along the adiabat, respectively. Note that ohmic dissipation and heat conduction are actually entropy sinks. The individual contributions to the entropy balance are given by 


$$
\begin{aligned}
& E_{S}=-\int \rho_{c} C_{c}\left(\frac{1}{T_{c}}-\frac{1}{T}\right) \frac{\mathrm{d} T_{c}}{\mathrm{~d} t} \mathrm{~d} V ; \\
& E_{g}=\frac{Q_{g}}{T_{c}}=\frac{1}{T_{c}} \int \psi \frac{\partial \rho_{c}}{\partial t} \mathrm{~d} V \\
& E_{L}=L_{H}\left(\frac{1}{T_{c}}-\frac{1}{T}\right) \frac{\mathrm{d} m_{i}}{\mathrm{~d} t} ; \\
& E_{\mathrm{rad}}=\int \rho_{c} h\left(\frac{1}{T_{c}}-\frac{1}{T}\right) \mathrm{d} V ; \\
& E_{\mathrm{ad}}=\int k_{c}\left(\frac{\nabla T}{T}\right)^{2} \mathrm{~d} V .
\end{aligned}
$$

Here, $T_{c}$ is the temperature at the CMB, $Q_{g}$ is the heat carried by chemical convection, $\Psi$ the gravitational potential, $C$ the concentration of the light alloying element, $L_{H}$ the latent heat, $\mathrm{d} m_{i} / \mathrm{d} t$ the rate of change of solidified mass, and $h$ the internal heating rate. For the classical case of innercore growth, as applicable to the Earth, the terms $E_{S}, E_{g}$, and $E_{L}$ can be expressed as functions of the radial growth rate of the inner core (e.g., Labrosse 2003; Nimmo 2007).

Since dissipation always produces entropy, $E_{\Phi}$ has to be greater than zero for a dynamo to occur. The entropy balance also illustrates the importance of core freezing for a dynamo because compositional buoyancy is not limited by the thermodynamic (Carnot) efficiency factor $\left(1 / T_{c}-{ }^{1} / T\right)$. For a purely thermal dynamo $\left(E_{g}=E_{L}=0\right)$ and assuming no internal heat sources in the core, the heat flux from the core needs to be greater than the heat flux along the core adiabat.

The volumetric ohmic dissipation rate is then calculated as

$$
\phi=\frac{E_{\Phi} T}{V_{\mathrm{fl}}},
$$

where $V_{\mathrm{fl}}$ is the volume of the fluid core and $T$ the characteristic core temperature where most entropy is produced.

In addition to constraints to the power available to generate a dynamo, the magnetic Reynolds number must be greater than a numerically defined critical value of about 50 (Christensen and Aubert 2006). The magnetic Reynolds number characterizes the importance of magnetic advection versus magnetic diffusion and is defined as $\operatorname{Re}_{m}=v L /$ $\eta$, where $v$ is the characteristic velocity, $L$ the characteristic length (the thickness of the convective shell, $D=L$ ), and $\eta$ the magnetic diffusivity. The characteristic velocity can be expressed through a scaling law,

$$
v \approx 0.7\left(\frac{D}{\Omega}\right)^{1 / 5}\left(\frac{\Phi}{\rho_{c}}\right)^{2 / 5}
$$

where $\Omega$ is the rotation rate and $\rho_{\mathrm{c}}$ is the average density of the fluid core.
In conclusion, whether a terrestrial planet features core convection and whether it can have a thermal or a chemical dynamo in these models depends mainly on the cooling rate of the core, the core temperatures, and the core melting temperatures. Thermal evolution models suggest that the existence of a present-day magnetic field in a terrestrial planet requires a crystallizing core. A purely thermally driven dynamo is unlikely for any present-day terrestrial planet, since the models typically predict a slowly cooling core with a core heat flux that is smaller than the heat flux along the core adiabat. In fact, a thermal dynamo is, in general, difficult to obtain for stagnant-lid planets. For these, superheating of the core with respect to the mantle must be postulated (e.g., Stevenson et al. 1983; Breuer and Spohn 2003; Laneuville et al. 2014). If superheating can be obtained (e.g., upon core formation), the thermal dynamo typically shuts off very early during the evolution, since the heat flow from the core decreases rapidly during the first few hundred million years. Considering the high values for the thermal conductivity recently suggested, early thermal dynamos would either be even more short-lived or entirely absent. Whether an inner core can grow (and by which crystallizing mechanism) and whether a compositional dynamo can be initiated depends strongly on the temperature evolution, the core pressure, and the core composition (melting temperature).

\section{Core composition}

Cosmochemical abundances suggest that the bulk of the core is made of iron, with some $\mathrm{Ni}$ and light elements. In addition to cosmochemical arguments, light elements are required to balance the density deficit of the Earth's outer fluid core compared with pure fluid iron and of the solid inner core with respect to pure solid iron (e.g., McDonough 2014). It is commonly assumed that sulfur is the most likely candidate for the light elements in the cores of terrestrial planets and moons (e.g., Ringwood 1977; McCammon et al. 1983). First, it is abundant in the solar system and is a siderophile (an element that is preferentially enriched in the iron melt), and it is thus likely enriched in the core upon core formation. Second, iron meteorites consist of pure $\mathrm{Fe}-\mathrm{Ni}$, with varying amounts of sulfides $(\mathrm{FeS})$. These meteorites are believed to be remnants of iron-rich cores from planetesimals that have differentiated during their early evolution and are considered building blocks of the terrestrial planets. The $\mathrm{Fe}-\mathrm{FeS}$ system is a eutectic system. It is usually assumed that the compositions of most terrestrial planets are on the Fe-rich side of the eutectic composition (e.g., Lodders and Fegley 1998), while for the large Jovian moons (e.g., Scott et al. 2002) and Mars (e.g., Stewart et al. 2007), this is under debate.

Many models of core processes simply assume an $\mathrm{Fe}-$ FeS composition. This assumption is almost certainly 
an oversimplification. We know from the Earth's core that light elements such as $\mathrm{Si}, \mathrm{O}, \mathrm{C}$, and $\mathrm{H}$ are likely incorporated in the core (for recent reviews, see, e.g., Hirose et al. 2013; McDonough 2014; Nimmo 2015). The actual composition of the core depends strongly on the primordial composition of the planet's forming material and the partition coefficient of light elements between the solid and liquid phases, which again depends on temperature and pressure conditions, as well as on the oxidation state during core formation: the abundance of light elements in the iron-rich cores will, therefore, vary among planets and moons. Even for the Earth's core, the core composition is not well-known and compositional models for the core (e.g., a silicon- versus an oxygen-bearing core) are offered as competing hypotheses (e.g., McDonough 2014). In contrast to other terrestrial bodies, compositional models for the Earth's core can be constrained by seismological data (e.g., Badro et al. 2014).

Knowing the light elements and their concentrations is important for modeling the thermal and the magnetic field evolution, for two main reasons. First, the melting relations pertaining to the core depend on the nature and concentrations of the light elements. For instance, the eutectic temperatures in the $\mathrm{Fe}-\mathrm{FeS}$ and $\mathrm{Fe}-\mathrm{Fe}_{3} \mathrm{C}$ systems are about 1000 and $500 \mathrm{~K}$ lower, respectively, than the melting temperature of pure iron at $25 \mathrm{GPa}$ (Chabot et al. 2008; Buono and Walker 2011). Second, the buoyancy forces powering the dynamo depend strongly on the density difference between the solid and the fluid phases. In the $\mathrm{Fe}-\mathrm{FeS}$ system, for instance, pure Fe is crystallizing (including a small amount of sulfur at higher pressure; $\mathrm{Li}$ et al. 2001), thereby maximizing the effects of the enrichment of light elements in the outer core and the density difference between the outer and the inner cores. In the Fe-Si system, alloys of $\mathrm{Fe}$ and $\mathrm{Si}$ form a solid solution with maximum compositional differences of $\sim 2$ wt.\% Si between the liquid and solid at $21 \mathrm{GPa}$ and temperatures $<2000 \mathrm{~K}$ (Kuwayama and Hirose 2004), and only a small density difference is expected, which is mainly due to the volume change upon crystallization. For more complex, multicomponent systems, melting temperatures and density differences are less well studied. First steps have been taken to explore the Fe-Si-S system (e.g., Sanloup and Fei 2004; Siebert et al. 2004; Malavergne et al. 2007) and the Fe-O-S system (e.g., Naldrett 1969; Urakawa et al. 1987; Tsuno and Ohtani 2009).

Another important issue for magnetic field generation is the presence of radioactive elements in the core, since these can provide additional power for the dynamo (see Eq. 6). In general, uranium, thorium, and potassium are lithophile elements that will not easily partition into the core (for reviews, see Roberts et al. 2003; McDonough 2014). Thermal models usually neglect them, although at least potassium has been discussed (e.g., Lewis 1971; Murthy 1991; Breuer and Spohn 1993; Buffett 2002). Recent experimental studies found that $\mathrm{K}$ increasingly partitions into Fe liquids at high pressures and temperatures with increasing concentrations of S or Ni (Gessmann and Wood 2002; Murthy et al. 2003; Lee et al. 2004). For Mars, a value of about $150 \mathrm{ppm} \mathrm{K}$ in the core has been suggested (Murthy et al. 2003), which has only minor effects on the planet's thermochemical evolution, however (Williams and Nimmo 2004). In addition, at very low oxygen fugacities, as suggested for Mercury's interior, elements that are typically considered lithophile can become more siderophile or chalcophile. This has been shown for $U$ (Malavergne et al. 2007) and is also possible for Th (Malavergne et al. 2010).

\section{Mercury}

The MESSENGER mission, which orbited Mercury between March 2011 and the end of April 2015, confirmed the presence of an internally generated magnetic field (Anderson et al. 2011), which had already been detected during the first and third close encounters of Mariner 10 in 1974 and 1975 (Ness et al. 1974, 1975, 1976; Connerney and Ness 1988; Russell et al. 1988). Mercury's magnetic field features a peculiarly small dipole moment, which is a factor of about $10^{4}$ smaller than that of the Earth. MESSENGER found the equivalent dipole to be offset toward the north by about 0.2 planetary radii, suggesting a strong quadrupole contribution, and a small deviation from axial symmetry (Anderson et al. 2012; Johnson et al. 2012). Moreover, evidence for remanent crustal magnetization was found as the spacecraft was spiraling toward Mercury to hit the surface on 30 April 2015. The cratering record of the magnetized surface suggests that a magnetizing field has existed since at least 3.73.9 Ga (Johnson et al. 2015).

Since the discovery of Mercury's magnetic field, it has mostly been argued that a hydromagnetic dynamo driven by chemical convection in an outer liquid core provides the best explanation, although alternative dynamo mechanisms have been suggested as well (see below). It is generally accepted that Mercury has an iron-rich core. The high density of the planet suggests that this core must be comparatively large, about 0.8 planetary radii. Recent MESSENGER gravity data (Smith et al. 2012) and the amplitude of libration measurements with Earth-based radar (Margot et al. 2007, 2012) have been used to calculate improved values of the planet's moment of inertia factor, $C$, and the ratio of the moment of inertia of the solid part of the planet overlying the liquid core to that of the whole planet, $C_{m} / C$, following Peale (1976). From these, improved estimates of the core radius range between 1840 and $2040 \mathrm{~km}$ (Smith et al. 2012; Hauck et al. 2013; Rivoldini and Van Hoolst 2013). The value of $C_{m} / C=0.431 \pm 0.025$ also supports the presence of a fluid outer core (Peale 1976; Margot et al. 2012). In a recent study, these data have been used to constrain the size of the putative inner core (Dumberry and Rivoldini 2015). 
Assuming an Fe-FeS core composition, the largest innercore radius consistent with the geodetic observations is $1325 \pm 250 \mathrm{~km}$.

Prior to the MESSENGER observations, the planet's bulk composition, including that of the core, was poorly constrained. Generally, a low volatile content was assumed because of Mercury's close orbital position to the Sun and its unusually large metal-to-silicate ratio suggested by the average density. Most models that aim to explain the large core radius predict a nearly complete loss of volatiles; i.e., a loss of silicates through evaporation (Fegley and Cameron 1987), high temperature equilibrium condensation of nebular materials (Lewis 1973), a giant impact removing part of the silicate planet (Cameron et al. 1988), or meteoritic mixing of refractory and volatile condensates (Morgan and Anders 1980). Measurements of the elemental ratios K/Th and K/U with the MESSENGER gamma-ray spectrometer (Peplowski et al. 2011, 2012), however, argue for a volatile content similar to that of the other terrestrial planets and thus may also allow for a higher volatile content in Mercury's core than previously assumed. Note that this assumption is still uncertain, because up to $10 \%$ of Mercury's U inventory, and possibly also a significant amount of Th, may have partitioned into the core (McCubbin et al. 2012) and thereby changed the elemental ratios $\mathrm{K} / \mathrm{Th}$ and $\mathrm{K} / \mathrm{U}$ if Mercury's core formed under extreme reducing conditions.

As for the other terrestrial planets, sulfur has been the most likely candidate for the light element in the iron core (e.g., Ringwood 1977; McCammon et al. 1983). However, the model of an $\mathrm{Fe}-\mathrm{FeS}$ core has recently been questioned, since the MESSENGER $x$-ray spectrometer (XRS) data (Nittler et al. 2011; Weider et al. 2012) indicate strongly reducing conditions, which has been used to suggest a core containing $\mathrm{Si}$ as well as $\mathrm{S}$ (e.g., Malavergne et al. 2010; Chabot et al. 2014). The presence of silicon may have major implications for the core's structure and evolution (Smith et al. 2012; Hauck et al. 2013) and for the magnetic field evolution (see Fig. 6).

Thermal evolution models (Schubert et al. 1988; Hauck et al. 2004; Grott et al. 2011; Tosi et al. 2013) suggested that a typical evolution of the magnetic field starts with a thermally driven dynamo, followed by a chemically driven dynamo after the start of inner-core growth. Thermally driven dynamo action may cease before the inner core begins to freeze, in which case there would be a gap in the magnetic field history. Whether such a gap occurs and its length in time would depend on the value of the heat flow along the core adiabat and the core's volatile content. The larger the heat flux along the core adiabat becomes, the shorter the lifetime of a thermally driven dynamo is. Recent laboratory measurements for iron suggested a thermal conductivity of $113-125 \mathrm{~W} \mathrm{~m}^{-1} \mathrm{~K}^{-1}$ for Mercury core pressure and temperature conditions and a heat flow along the adiabat of $45-100 \mathrm{~mW} \mathrm{~m}^{-2}$ (Deng et al. 2013). This high value suggests a rapid decline of a thermal dynamo, within less than a few tens of Ma (e.g., Grott et al. 2011; Tosi et al. 2013): see Fig. 7c. Note, however, that volatiles in the core reduce the thermal conductivity and thus the heat flow along the adiabat (de Koker et al. 2012). This, in turn, increases the lifetime of an early thermal dynamo. On the other hand, the higher the volatile content is, the later the onset of inner-core growth occurs (e.g.,

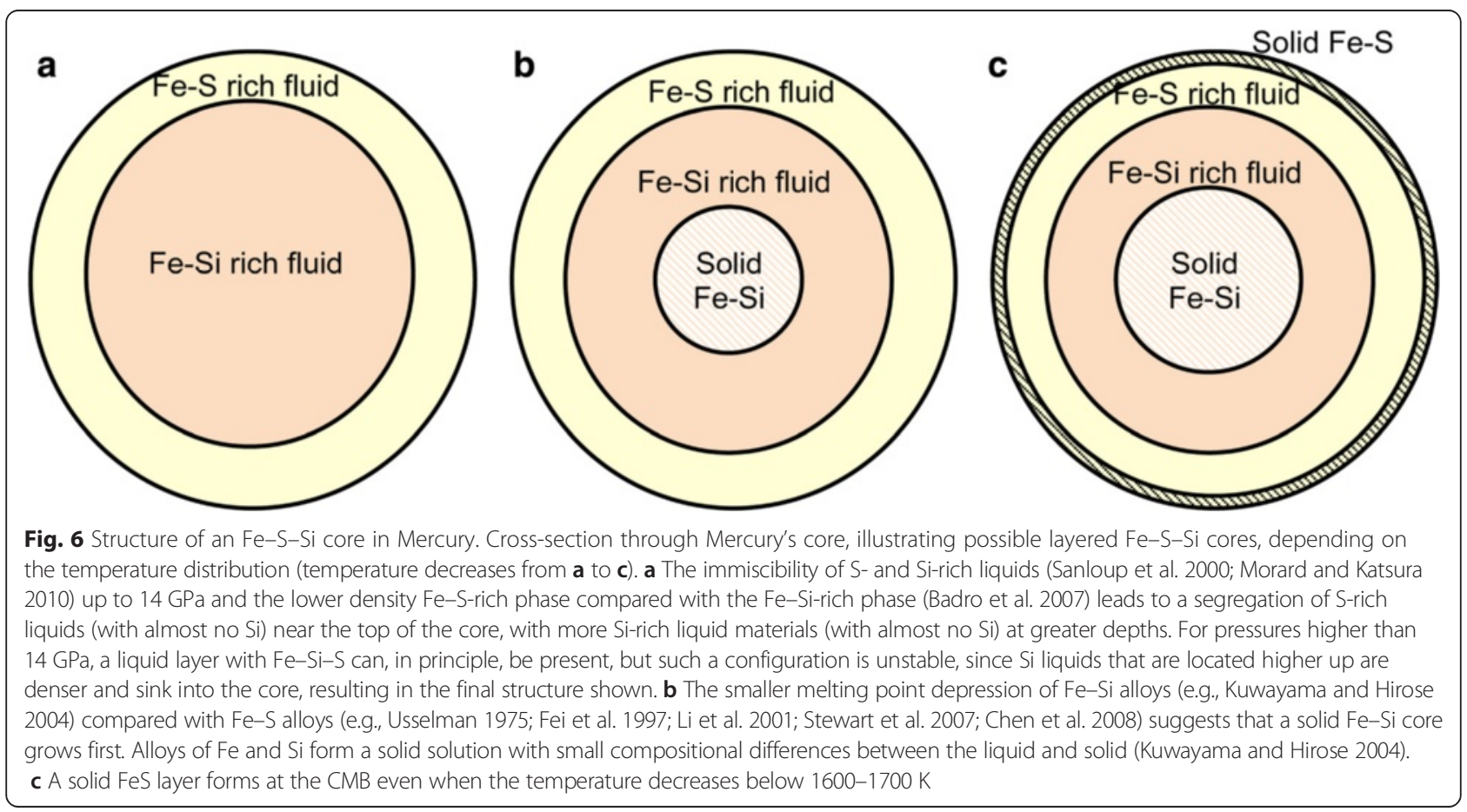



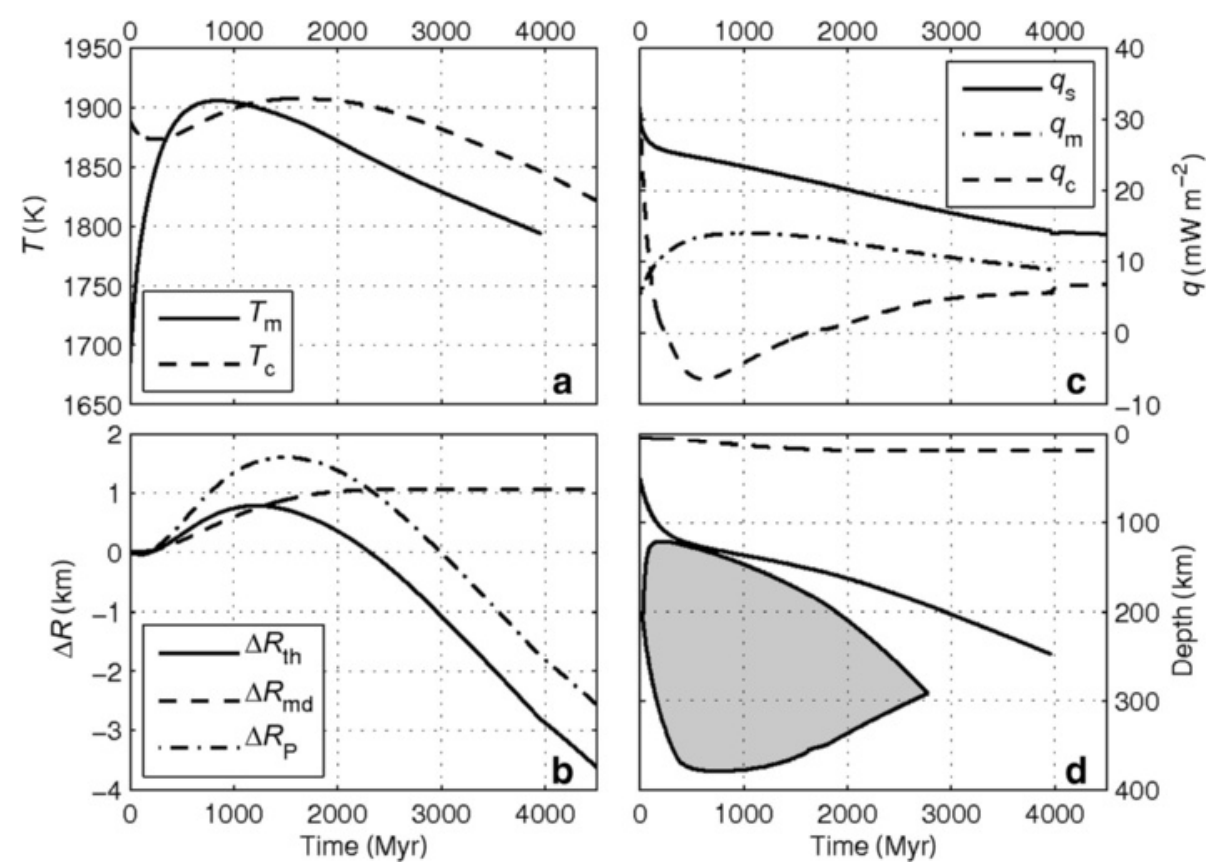

Fig. 7 Thermochemical evolution of Mercury. Representative $\mathbf{a}$ time evolution of mantle temperature and CMB temperature; $\mathbf{b}$ time evolution of the planetary radius change caused by thermal expansion/contraction of the mantle and core (solid line), mantle differentiation (dashed line), and sum of the two contributions (dash-dotted line); c time evolution of the surface heat flux (solid line), mantle heat flux (dash-dotted line), and core heat flux (dashed line); $\mathbf{d}$ time evolution of the thickness of the secondary crust (dashed line), the stagnant lid (solid line), and the region where partial melting occurs (shaded gray). Figure adapted from Tosi et al. (2013)

Schubert et al. 1988; Hauck et al. 2004; Grott et al. 2011; Tosi et al. 2013). For example, the core starts to freeze after $0.75,0.8$, and 2.5 Gyr for an initial concentration of $0.2,1$, and 5 wt.\% $\mathrm{S}$, respectively, assuming the same mantle parameters (Schubert et al. 1988).

The existence of a solid inner core places constraints on the volatile content of the core and an upper limit to the concentration can be derived depending on the radioactive heat source density in the mantle, the thermal history, the nature of the volatiles, and the details of the melting relations. The amount of contraction of the planet derived from the distribution, lengths, and heights of lobate scarps (e.g., Strom et al. 1975; Byrne et al. 2014), on the other hand, places constraints on the minimum amount of volatiles in the core, as well as on the cooling rate of the planet since the late heavy bombardment (LHB; Hauck et al. 2004; Breuer et al. 2007; Grott et al. 2011; Tosi et al. 2013). Before MESSENGER, the distribution and morphology of the scarps were thought to imply an average contraction of the planet's radius by only $1-2 \mathrm{~km}$ (Strom et al. 1975) since the LHB. From MESSENGER camera observations, a larger value of $4.2-6.3 \mathrm{~km}$ has recently been inferred (Byrne et al. 2014).

The most likely source of global contraction is a combination of thermal contraction (caused by cooling) and a volume change through solidification of parts of the core, with core freezing contributing more effectively. Complete solidification of a purely iron core would shrink the planet by about $17 \mathrm{~km}$ in radius (Solomon 1976). This effect can be considerably amplified if a light alloying element such as sulfur is present in the core, which is expelled from the inner core upon solidification, increasing the density difference between the liquid and solid core phases. The radius of the inner core can thus be taken as roughly proportional to the amount of planetary contraction (Hauck et al. 2004; Breuer et al. 2007; Grott et al. 2011; Tosi et al. 2013). Considering a value of $\sim 7 \mathrm{~km}$ (Byrne et al. 2014) and assuming that it is entirely caused by the volume change owing to inner-core growth, an inner-core radius of $~ 800-$ $1000 \mathrm{~km}\left(0.4-0.5 R_{c}\right.$; Grott et al. 2011) is obtained. The inner solid core is likely smaller, however, because of secular cooling contributing to the radial contraction. A larger solid inner core can only be reconciled with the observed contraction data if most of the inner core formed during the first $500 \mathrm{Ma}$ before the LHB (e.g., Schubert et al. 1988), thereby erasing the geological evidence of early contraction.

Models that consider the combined thermal, magmatic, and tectonic evolution of Mercury (Hauck et al. 2004) suggest a bulk core sulfur content between 6.5 and 7.5 wt.\% and a late formation of the inner core since $1 \mathrm{Ga}$. These authors further argued that acceptable models will require a dry-olivine mantle rheology and that heat production is 
provided by thorium only, as predicted by the formation model with late evaporation of silicates (Fegley and Cameron 1987). The more recent models of Grott et al. (2011) and Tosi et al. (2013) predicted similar values of the sulfur content (6-10 wt.\%) to explain the global contraction, even when considering a non-refractory composition consistent with the MESSENGER gamma-ray spectrometer data (Peplowski et al. 2011, 2012) if the insulating effect of a regolith layer is included (see Fig. 7b). Combined, the results of thermochemical evolution models suggest that dynamo action in Mercury to produce the present field is recent and that the observed early magnetic field episode was likely brief.

The classical hydromagnetic dynamo, as assumed in the thermal evolution models above, has problems to explain the strength of Mercury's magnetic field, however. Estimates from scaling laws such as Eq. 9 above suggest a much stronger field than observed (Stevenson et al. 1983; Schubert et al. 1988; Wicht et al. 2007). Other models that predict a strong quadrupole component (e.g., Christensen 2006; Christensen and Wicht 2008) imply a large dipole tilt, which has not been observed. A recent review of the various dynamo models for Mercury can be found in Wicht and Heyner (2014). We only provide a summary here.

Thin-shell dynamo models with a large inner core (relative inner-core size larger than about 0.8) can produce magnetic fields with Mercury-like field strengths (Heimpel et al. 2005; Stanley et al. 2005), but these models are not consistent with geodetic and tectonic observations (Grott et al. 2011; Dumberry and Rivoldini 2015). Alternatively, a deep dynamo with a small inner core (of less than $1000 \mathrm{~km}$ in radius) has been proposed by Heimpel et al. (2005), Christensen (2006), and Christensen and Wicht (2008). In the latter two models, the dynamo operates below a stable conducting layer in the outermost core. The field is then strongly attenuated by the electromagnetic skin effect of the stagnant (i.e., no vertical movement) but electrically conducting layer. However, the stagnant layer may be destabilized by double diffusive effects, which can only be avoided if the sulfur concentration in Mercury's core is very small, only a fraction of a percent (Manglik et al. 2010). A core with such a low sulfur concentration is again not likely to be consistent with the geodetic and tectonic evidence (Hauck et al. 2004; Grott et al. 2011; Tosi et al. 2013).

These dynamo models assume an Earth-like dynamo with inner-core freezing starting at the center. However, as discussed before, recent data about the melting relations of $\mathrm{Fe}-\mathrm{FeS}$ at moderate pressures suggest a negative liquidus temperature gradient in the outer layers of the Hermean core. The present core would then most likely be precipitating solid iron in the form of snow at a single depth or in two distinct zones (Chen et al. 2008). Such a scenario predicts a stably stratified layer in the outermost core, as required to explain the geometry and magnetic field strength through the electromagnetic skin effect (Christensen 2006; Christensen and Wicht 2008; Vilim et al. 2010). However, dynamo models that include an iron snow layer are strongly time dependent and generate Mercury-like magnetic fields only for a fraction of the total simulation time (Wicht and Heyner 2014). Large-scale variations in the CMB heat flux may help to stabilize strong Mercury-like quadrupole terms (Cao et al. 2014), but these are not consistent with the current understanding of Mercury's lower mantle (e.g., Tosi et al. 2013).

Motivated by the findings produced by the MESSENGER XRS instrument (Nittler et al. 2011), Si has been suggested as a core phase in addition to S (Malavergne et al. 2010), which may have strong implications for the core structure and evolution (Smith et al. 2012; Hauck et al. 2013). Highpressure experiments with the $\mathrm{Fe}-\mathrm{S}-\mathrm{Si}$ ternary system (e.g., Malavergne et al. 2010) have revealed an immiscibility of Sand Si-rich liquids up to a pressure of $\sim 14 \mathrm{GPa}$ (Sanloup and Fei 2004; Morard and Katsura 2010) and smaller density differences between liquid and solid phases compared with those in the $\mathrm{Fe}-\mathrm{S}$ binary system (Kuwayama and Hirose 2004). These findings suggest a compositional stratification in the core as S-rich liquids would segregate toward the $\mathrm{CMB}$, leaving more $\mathrm{Si}$-rich materials at greater depths (Malavergne et al. 2010; Smith et al. 2012; Hauck et al. 2013; see Fig. 6). Hauck et al. (2013) even suggest that the outer FeS layer is solid and part of the solid outer shell (crust, mantle, and upper core), whose thickness has been estimated from the moment-ofinertia data. This would imply a mantle even thinner than $400 \mathrm{~km}$ and require core-mantle temperatures lower than that for the liquidus of pure FeS (1600-1700 K, depending on the pressure at the CMB; Boehler 1992). These temperatures are not consistent with the most recent thermal evolution models (Tosi et al. 2013; see Fig. 7a). The implications of an $\mathrm{Fe}-\mathrm{S}-\mathrm{Si}$ system for the dynamo are, however, unknown.

The present magnetic field data do not allow us to conclusively prove or reject the various dynamo models and thermal history calculations. More details about the magnetic field are expected from the upcoming BepiColombo mission, and new constraints may be derived for the dynamo. BepiColombo consists of two orbiters in different orbits (characterized by small and large eccentricities), both equipped with magnetic field sensors that may help to better disentangle the magnetic field of the planet.

\section{The moon}

Lunar paleomagnetic data suggest a magnetizing field of up to $\sim 100 \mu \mathrm{T}$ between at least 4.25 and $3.56 \mathrm{Ga}$ b.p., a field similar in strength to the present terrestrial magnetic field (Cisowski and Fuller 1986; Garrick-Bethell et al. 2009; Shea et al. 2012; Tikoo et al. 2012; Suavet et al. 2013). The field 
strength decreased by an order of magnitude between 3.56 and $~ 3.3$ Ga b.p. (Tikoo et al. 2012, 2014) and possibly persisted until 3.19-1.3 Ga b.p. (Tikoo et al. 2014) or even until 200 Ma b.p. (Wieczorek et al. 2006) at a level of a few nano-Teslas (see Fig. 8). The paleomagnetic data younger than $3.19 \mathrm{Ga}$ are, however, also consistent with no field, and further laboratory analysis is needed. Alternative explanations to a dynamo-generated global field for the lunar magnetic record suggest that at least part of the remanent magnetization was acquired from plasma clouds that had been generated by impacts antipodal to the magnetic anomaly (Hide 1972; Hood and Vickery 1984; Hood and Huang 1991; Hood et al. 2001). A comprehensive review of the Apollo-era measurements and recent paleomagnetic studies can be found in Weiss and Tikoo (2014).

A lunar dynamo requires an iron-rich core, whose existence is largely uncontroversial. A core of $250-450 \mathrm{~km}$ radius is consistent with both the lunar polar moment of inertia (Konopliv et al. 1998) and electromagnetic sounding data from the Lunar Prospector (Hood et al. 1999; Shimizu et al. 2013). Reanalyses of Apollo seismic data (Garcia et al. 2011; Weber et al. 2011) have confirmed the existence of a core with a radius between 340 and $420 \mathrm{~km}$ but disagree on the existence of a solid inner core. Recent analysis of lunar laser ranging data by Williams and Boggs (2015) required a region of high dissipation with a radius $\geq 535 \mathrm{~km}$, consistent with a (partially molten?) high-dissipation layer on top of a core (see also Weber et al. 2011).

The paleomagnetic data show characteristic features that any magnetic field generation model needs to explain. First, there is no remanently magnetized rock older than $4.25 \mathrm{Ga}$.

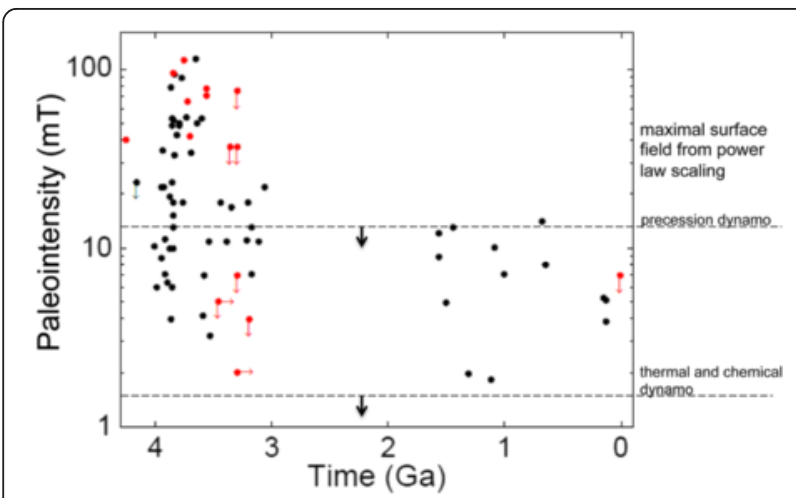

Fig. 8 Paleomagnetic data of the Moon. Summary of lunar paleomagnetic data. Black points represent Apollo-era measurements (Fuller and Cisowski 1987; Wieczorek et al. 2006) and red points indicate modern, more reliable data produced using the isothermal remnant magnetization (IRM) and Thellier-Thellier methods (Weiss and Tikoo 2014). Arrows indicate data points that only provide an upper limit to the field strength and/or age. The two horizontal dashed lines represent the calculated maximum surface field obtained from the power scaling law (Eq. 9) for both precession dynamo (Dwyer et al. 2011) and thermal and/or chemical dynamo (Evans et al. 2014; Laneuville et al. 2014). Figure adapted from Scheinberg et al. (2015)
Two alternative explanations have been suggested. (1) The remanent magnetization of older crustal rock could have been destroyed by impact gardening and/or volcanic activity in the first $250 \mathrm{Ma}$ failed to produce enough rock that could have acquired significant remanent magnetization. Alternatively, (2) the internal field may have been triggered only about $250 \mathrm{Ma}$ after core formation. Second, the paleointensity between 3.56 and $3.85 \mathrm{Ga}$ b.p., inferred for the magnetizing field from the measured magnetization, was about two orders of magnitude higher than suggested by estimates from magnetic field scaling laws for typical thermal or chemical dynamos (e.g., Evans et al. 2014; Laneuville et al. 2014; Weiss and Tikoo 2014). Finally, no lunar dynamo model exists to date that is capable of explaining the rapid decline of the field intensity with time until $3.3 \mathrm{Ga}$ b.p. while continuing to produce a weak field thereafter (but still one order of magnitude larger than that from conventional dynamo scaling models). The latter predict fields of about $1 \mu \mathrm{T}$ or smaller.

Most previous thermal and magnetic field evolution models have considered a thermally driven dynamo during the early evolution of the Moon (Konrad and Spohn 1997; Spohn et al. 2001; Laneuville et al. 2014). These models show that a thermally driven dynamo would have been active since core formation and may have lasted a maximum of $500 \mathrm{Myr}$, until $4 \mathrm{Ga}$ b.p., if the core was superheated by a few hundred degrees with respect to the mantle. These thermal evolution models, however, neglect any chemical stratification of at least the lower mantle. A recent study by Evans et al. (2014) showed a long-standing thermal dynamo of up to $2 \mathrm{Gyr}$ if the lower mantle rheology is weakened by water, but they also assume a low thermal conductivity of the iron-rich core of $25 \mathrm{~W} \mathrm{~m}^{-1} \mathrm{~K}^{-1}$ and an adiabatic heat flux of $2.4 \mathrm{~mW} \mathrm{~m}^{-2}$.

Models of a late onset of dynamo action invoked the thermal and chemical consequences of a magma ocean (Stegman et al. 2003; Zhang et al. 2013). After crystallization of the magma ocean, a dense ilmenite and pyroxene cumulate layer, located just below the enriched KREEP layer, sinks to the deep lunar mantle and thermally insulates the core. (The KREEP layer is enriched in potassium (K), rare earth elements (REE), and phosphorous (P).) The core is thus prevented from cooling convectively and also from developing a dynamo. Eventually, because of the heating by radiogenic elements, the dense lower mantle becomes buoyant and convection currents rise toward the surface. With the removal of the thermal blanket, the core begins to convect vigorously, cooling and producing a short-lived thermal dynamo, although the heat flux from the core is less than $8 \mathrm{~mW} \mathrm{~m}^{-2}$ in that scenario and, therefore, is just at the limit of or even below the critical heat flux along the adiabat. The period it takes the thermal blanket to heat up and rise back toward the surface is essential in these models and is broadly consistent with the time of 
the eruption of the mare basalts and the magnetization of lunar rocks between $4.25 \mathrm{Ga}$ and $3.55 \mathrm{Ga}$ b.p.

Other models explain the magnetic signatures by mechanically stirring the core through either precession (Williams et al. 2001; Dwyer et al. 2011) or changes in the lunar rotation rate from large impacts (Le Bars et al. 2011). In particular, the precession dynamo (see Fig. 9) can be long lasting (until 3.4-2.5 Ga b.p.) and may be capable of producing the strong surface magnetization, since the power caused by differential motion can be much larger compared with the power driving thermal or chemical convection (Tian et al. 2014). Although the precession dynamo can be viable for the strong early lunar field, the possible long-lasting and weak field until recent times may still require an alternative explanation.

A recent interpretation of Apollo seismic data suggested that the core may be stratified with a liquid outer and a solid inner core (Weber et al. 2011) of $240 \mathrm{~km}$ radius. The core radius is $330 \mathrm{~km}$ in this model. If correct, a chemical dynamo may become a viable alternative, a possibility that has been discarded by previous evolution models (e.g., Konrad and Spohn 1997). These latter authors argued that the absence of a present-day magnetic field would be difficult to reconcile with a growing inner core and a chemical dynamo supporting inner-core growth would be difficult to stop in a continuously cooling planet. This is consistent with the conclusion of Laneuville et al. (2014) but inconsistent with that of Scheinberg et al. (2015). In the former study, however, the authors neglected the partial derivative of the liquidus temperature owing to light-element enrichment in the outer core, similar to the approach of Nimmo (2007). Considering this contribution, sufficient power is indeed not available to drive a presentday dynamo, even with a growing inner core (Scheinberg

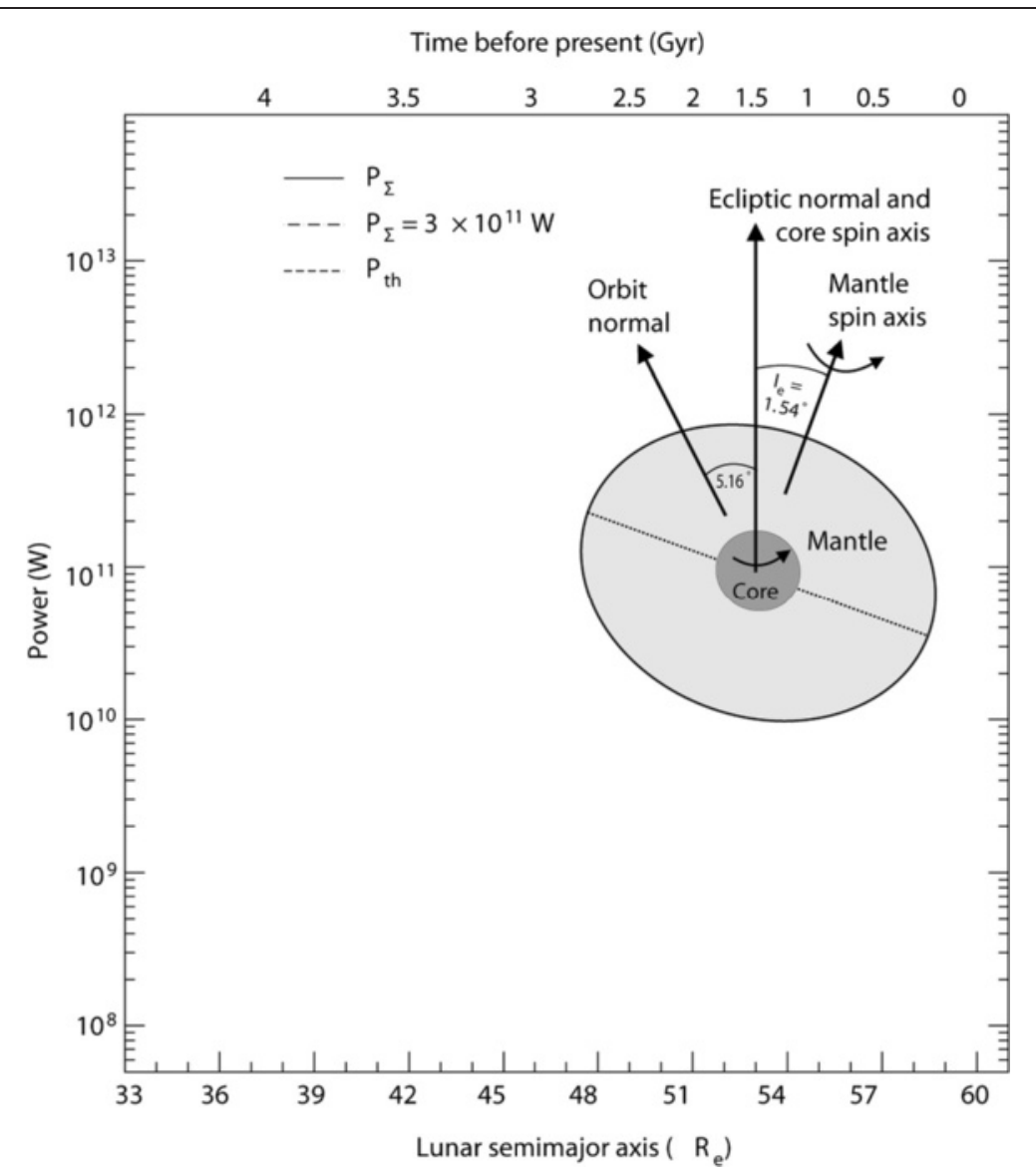

Fig. 9 Precession dynamo: the total power deposited into the lunar core. The solid line shows the total power deposited into the lunar core, $P_{\Sigma,}$ as a function of semimajor axis (bottom $x$ axis) for a precession dynamo: continuous mechanical stirring caused by the differential motion, due to Earth-driven precession of the lunar spin axis, between the solid silicate mantle and the liquid core below. The adiabatic threshold value is marked as $P_{\text {th }}$ (dashed line). The dash-dotted line is for $P_{\Sigma}=3 \times 10^{11} \mathrm{~W}$, which represents an estimate of the power available to drive the dynamo in the Earth. The time before the present is plotted at the top. There is $7 \times 10^{28} \mathrm{~J}$ of energy available for dynamo generation between the time of the Cassini state transition (at a lunar semimajor axis of $34 R_{\mathrm{E}}$ ) and the cessation of the dynamo (when the power decreases to below $P_{\text {th, }}$ i.e., $\sim 2.8$ Ga b.p.). The results suggest that a mechanically driven dynamo could persist for at least 1.6 Gyr. The inset shows the geometry of the situation. The mean motion, $n$, of an orbit is related to the semimajor axis, $a$, through $n=\left(G M_{e} / a^{3}\right)^{0.5}$, where $M_{e}$ is the mass of Earth. Figure after Dwyer et al. (2011) 
et al. 2015). The growth rate of the core and, therefore, the compositional buoyancy becomes too small to overcome the stable temperature gradient for subadiabatic core cooling. These models, which assume Earth-like core crystallization, further suggest a field strength that is two orders of magnitude too low to explain the observed early strong magnetization and one order too low to explain the weaker, younger magnetization (Laneuville et al. 2014). Alternatively, for a sulfur content above about $8 \mathrm{wt} . \%$, iron snow fall is a likely mechanism for core solidification (Laneuville et al. 2014), as has been suggested for Ganymede (e.g., Hauck et al. 2006), Mars (Stewart et al. 2007), and Mercury (Chen et al. 2008). In the iron snow regime, the formation and growth of the inner core would mark the demise of dynamo action (Christensen 2015; Rückriemen et al. 2015).

\section{Mars}

Since the Mars Global Surveyor (MGS) mission (Acuña et al. 1998, 1999, Mitchell et al. (2001); Connerney et al. 1999), it has been known that the crust of Mars is remanently magnetized (see Fig. 10) and that the planet must have had an active magnetic field of significant strength some time during its history, most likely in the Early Noachian. The magnetization of up to $\sim 10-$ $30 \mathrm{~A} \mathrm{~m}^{-1}$, comparable in magnitude to the remanent magnetization of fresh extrusive basalt near the oceanic ridge axes of Earth (Bleil and Petersen 1983), suggests a magnetizing field of 0.1 to 10 times that of the present Earth (Mitchell et al. 1999, 2001; Ness et al. 1999), depending on the mineralogy and the magnetic microstructure of the Martian crust. The magnetic history of the planet has been reviewed in a number of publications (e.g., Connerney et al. 2004; Breuer et al. 2010; Breuer and Moore 2015; Connerney 2015), some of which discuss the subject in comparison with the histories of other terrestrial planets, and we will therefore only briefly summarize the present knowledge.

The most popular model to explain an early magnetic field for Mars and the absence of a present dynamo field goes back to the work of Stevenson et al. (1983) and Schubert and Spohn (1990) who proposed, on the basis of their thermal history models, that the Martian core may be lacking an inner core and that an early thermally driven dynamo had ceased to operate after a few hundred million years of evolution. The model was subsequently refined (e.g., Spohn et al. 1998; Hauck and Phillips 2002; Breuer and Spohn 2003, 2006; Williams and Nimmo 2004; Michel and Forni 2011) and is roughly consistent with a dynamo lifetime of $500 \mathrm{Ma}$, as inferred from the magnetization pattern (Fig. 11). The timing has been questioned, however, by Schubert et al. (2000) who argue for younger magnetized rock on the surface, as suggested by the timing of magnetized volcanic units by Hood et al. (2010). The hypothesis of a magnetic field at epochs later than the Early Noachian is supported by the magnetization, albeit weak, of Martian meteorites with formation ages of $1.3 \mathrm{Ga}$ to $180 \mathrm{Ma}$. Their magnetization is consistent with a weak surface field of a few hundred to a few thousand nanoTeslas (Collinson 1997; Rochette et al. 2001). Although it cannot be excluded that the dynamo became somehow reactivated, it is more likely that the young Martian meteorites were magnetized by the older, strongly magnetized crust rock (for a review, see Connerney et al. 2004).

The hypothesis of the absence of an inner core can be tested based on geochemical evidence for the composition of the Martian core. A molten core for the entire evolution is possible if the core contains at least $\sim 5 \mathrm{wt} . \%$ of sulfur (Williams and Nimmo 2004), although the more recent Fe-FeS melting data of Stewart et al. (2007) suggest a sulfur threshold of at least $10 \mathrm{wt} . \%$ or even higher, depending on the efficiency of core cooling (see Fig. 12). In the latter study, it was also suggested that iron snow would become active in the future of Mars because of further cooling. A core sulfur concentration of $14.2 \mathrm{wt} . \%$ has been suggested (Dreibus and Wänke 1985; McSween 1985) based on chemical analysis of SNC meteorites. The estimate assumed, however, that the all available sulfur went into the core during core formation. Recent experiments showed that it is impossible to simultaneously account for the Martian mantle depletion of moderately siderophile elements if the Martian core sulfur content exceeds $10.5 \mathrm{wt} . \%$ under reducing conditions; i.e., one logarithmic unit below the iron-wüstite buffer (Rai and van Westrenen 2013). Note that these high sulfur concentrations also indicate the partitioning of oxygen into the core (Tsuno et al. 2011).

Alternative scenarios that explain the magnetic field history invoke changes in tectonic style and in the heat transport mechanism, from plate tectonics to stagnant lid (Nimmo and Stevenson 2000; Stevenson 2001; Breuer and Spohn 2003; see Fig. 11), or consider the effects of impacts. Some of the latter models suggest that a late impact may have heated the mantle to the extent that convection and dynamo action in the core stopped (e.g., Roberts et al. 2009; Arkani-Hamed and Olson 2010), while Reese and Solomatov (2010) argued that a late large impact may have triggered the onset of the dynamo. Which of these conflicting scenarios is more likely depends mainly on the dynamics in the core during the merging of an iron diapir with a preexisting core, a process that is poorly understood (Monteux et al. 2013).

The dichotomy of the observed magnetization, with the southern hemisphere being more strongly magnetized than the northern hemisphere (e.g., Langlais et al. 2004; Morschhauser et al. 2014), is an important feature that must be explained. Two general types of models have been suggested. A once more or less homogeneous magnetization may have been destroyed in the 


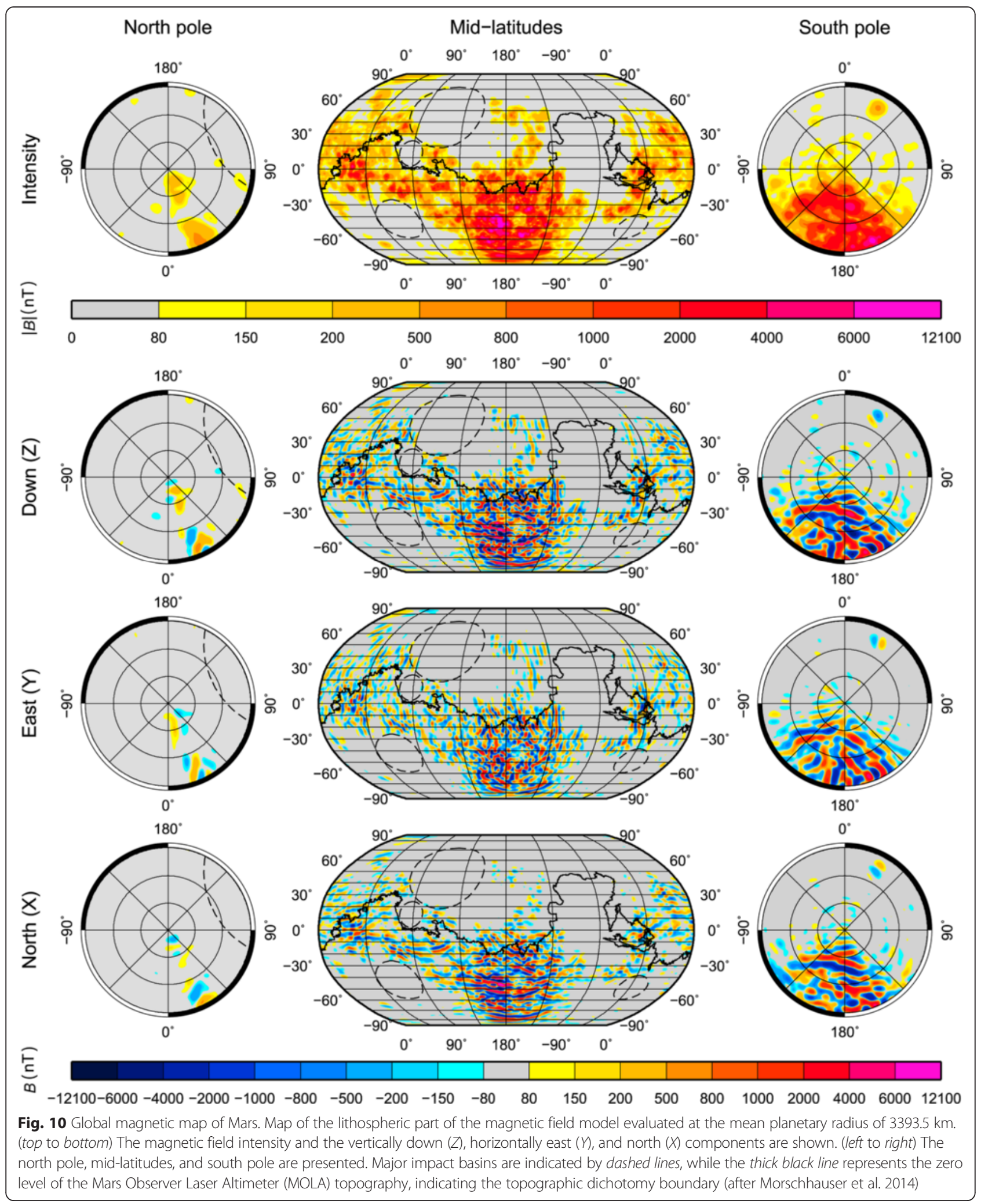

northern hemisphere by, for example, hydrothermal alteration (Solomon et al. 2005) or impacts (e.g., Rochette et al. 2003; Mohit and Arkani-Hamed 2004). The alternative explanation suggests that the dynamo itself produced a hemispherical field owing to lateral heat flow variations at the CMB (Stanley et al. 2008; Amit et al. 2011). This 


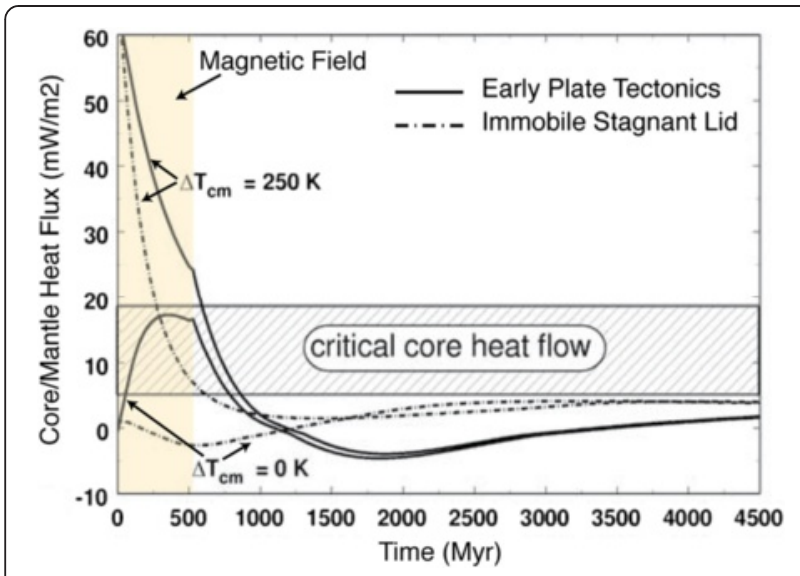

Fig. 11 Evolution of Martian core heat flow. Core-mantle heat flow as a function of time for models with early plate tectonics (solid line) and stagnant-lid convection throughout their entire evolution (dashed line), with initial temperature differences across the $\mathrm{CMB}$ of $\Delta T_{\mathrm{cm}}=0 \mathrm{~K}$ and $\Delta T_{\mathrm{cm}}=250 \mathrm{~K}$. The gray region marks the range of the critical coremantle heat flux along the adiabat and the orange region the suggested time period of the global magnetic field (after Breuer and Spohn 2003)

hemispherical dynamo would produce strong magnetic fields in the southern hemisphere if the heat flow from the core below the southern hemisphere was stronger than that below the northern hemisphere. A recent numerical model by Dietrich and Wicht (2013) showed, however, that these hemispherical dynamos reverse on timescales of about 10 kyr: too quickly to allow for the unidirectional magnetization of a thick crustal layer required to explain the strong magnetization in the southern hemisphere.

\section{Ganymede}

In 1996, the Galileo mission measured a magnetic field around the Jovian moon Ganymede (Kivelson et al. 1996), which was interpreted as a field of internal origin embedded in the Jovian magnetic field. The field would have an equatorial surface field strength of approximately $719 \mathrm{nT}$ (Kivelson et al. 2002). The discovery of a self-sustained magnetic field at Ganymede came as a surprise, since it was commonly believed that the icy moon-with an average density of $1936 \mathrm{~kg} \mathrm{~m}^{-3}$ - was composed of a rocky core surrounded by a large mantle of water or water ice with an ice surface. The magnetic field has an anomalously low quadrupole moment relative to its dipole moment (Kivelson et al. 2002), placing a strong constraint on the dynamo mechanism.

The origin of Ganymede's magnetic field is most likely found in an iron-rich core, because alternative mechanisms such as remanent magnetization of a silicate layer containing magnetic minerals below the ice mantle or a dynamo in an electrically conducting, salty subsurface ocean are implausible (Schubert et al. 1996). For remanent magnetization, both the concentration of magnetic minerals and the external field (i.e., the present Jovian magnetic field at Ganymede's orbit, 100 nT) are too low to reasonably explain the observed field. On the other hand, the flow velocity in its ocean must be implausibly large, on the order of $1 \mathrm{~m} \mathrm{~s}^{-1}$, to explain the observed magnetic field through a dynamo in a subsurface ocean.

The existence of an iron-rich core is further supported by the small mean moment-of-inertia factor $(\mathrm{MoI}=0.3105)$ derived from Galileo gravity and rotation data (e.g., Anderson et al. 1996; Sohl et al. 2002; Schubert et al. 2004). Fixing the

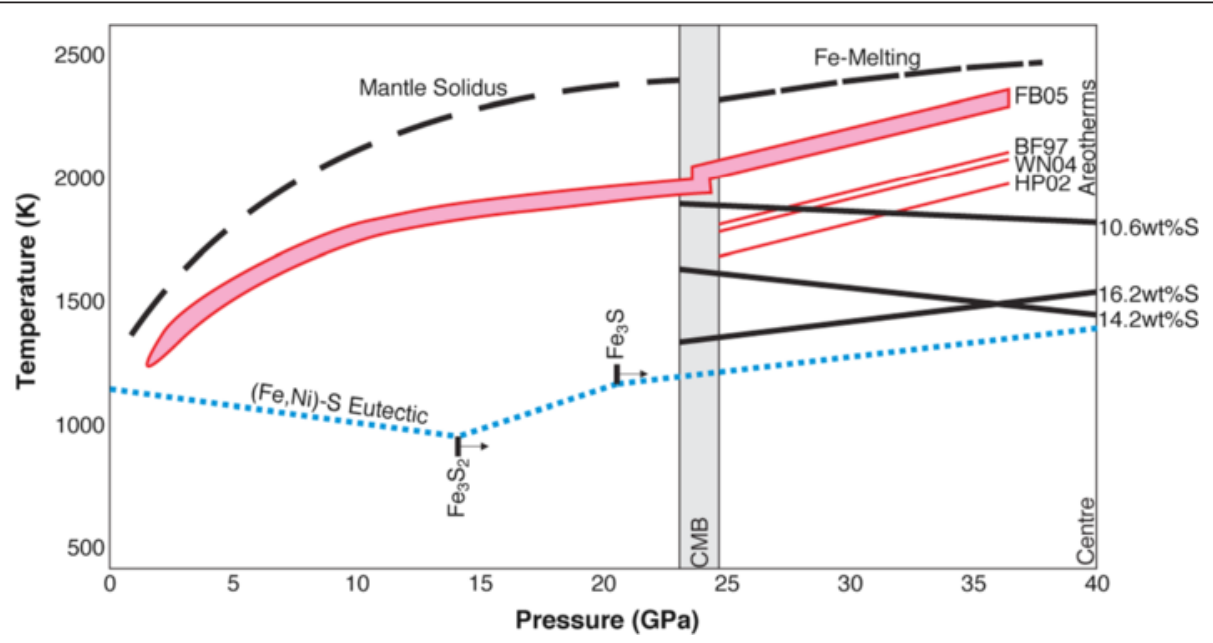

Fig. 12 Melting temperature of Mars core. Effect of pressure on the (Fe, Ni)-S system. Eutectic melting temperatures for (Fe, Ni)-S with Fe:Ni = 10.6:1 are shown as dotted blue lines. Eutectic temperature inflections around 14 and $20 \mathrm{GPa}$ are owing to the stabilization of Fe $\mathrm{S}_{2}$ and Fe $\mathrm{S}_{3}$ above these pressures. Liquidus temperatures for core S contents of 10.6, 14.2, and 16.2 wt.\% are presented as solid black lines. The 16.2 wt.\% curve has a positive slope, because its S content is higher than eutectic. Shown is the present-day mantle temperature profile and core adiabat of Fei and Bertka (2005), as well as the core adiabat based on CMB temperature determinations by Bertka and Fei (1997), Williams and Nimmo (2004), and Hauck and Phillips (2002) using parameters from Williams and Nimmo (2004). The pressure of the CMB, the mantle solidus, and the melting curve of pure Fe (Fei and Bertka 2005) are given for reference (after Stewart et al. 2007) 
silicate and ice-shell densities to plausible values and allowing for core compositions ranging from pure iron to pure FeS, Sohl et al. (2002) found core radii between $1 / 4$ and $1 / 3$ Ganymede radii for a three-layer model (see Fig. 13). As a light and siderophile element, sulfur is the main candidate (e.g., Schubert et al. 2004). Assuming a composition identical to a type I carbonaceous chondrite (CI), experiments by Scott et al. (2002) indicate that the alloying of iron and sulfur may form FeS-dominated cores. However, because of the unknown oxidation state of Ganymede's interior during core differentiation, it is difficult to say whether the core composition is likely to be of Fe- or FeS-rich eutectic composition.

Compositional-driven convection is the preferred mechanism for driving Ganymede's dynamo (Hauck et al. 2006; Bland et al. 2008) although Kimura et al. (2009) have suggested a model including a present-day thermal dynamo. This model could work if Ganymede accreted cold and was subsequently heated by the decay of radioactive elements. They assumed a thermal expansivity of $1.710^{-5} \mathrm{~K}^{-1}$, which is, unfortunately, not consistent with recent data for liquid iron at Ganymede's core pressure (e.g., Williams 2009), and they used a heat flux along the adiabat as small as $1 \mathrm{~mW} \mathrm{~m} \mathrm{~m}^{-2}$ to meet the necessary condition for a thermal dynamo.

The melting behavior of Fe-FeS alloys at Ganymede's core pressure, between 6 and $10 \mathrm{GPa}$ (Sohl et al. 2002),

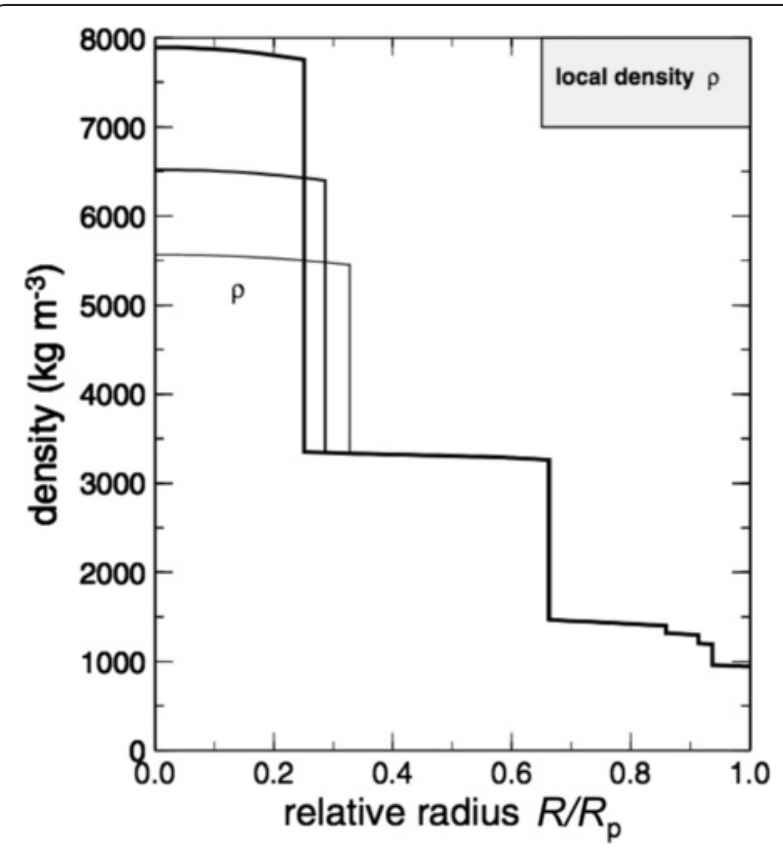

Fig. 13 Interior structure of Ganymede. Radial distribution of density as a function of the relative radius $\left(R / R_{p}\right)$ for variable core compositions of Ganymede (bold curve 100 wt.\% Fe; semi-bold curve 50 wt.\% Fe and 50 wt.\% FeS; light curve 100 wt.\% FeS). Figure after Sohl et al. (2002) motivated Hauck et al. (2006) to consider the iron snow model for Ganymede. In addition, they introduced an FeS flotation model (see above). Assuming a linear interpolation between the iron liquidus and the $\mathrm{Fe}-\mathrm{Fes}$ eutectic temperature, they found that Fe snow can occur for bulk core sulfur concentrations greater than $6 \mathrm{wt} . \%$ and FeS flotation for bulk core sulfur contents above $22.5 \mathrm{wt} . \%$. Recent data by Buono and Walker (2011), however, suggest that the iron snow regime should work even at sulfur concentrations below 6 wt.\%. Because of the pressure gradient in the core, it is possible that the iron snow regime is established in the outer core, while an inner core begins to freeze independently at the center for certain ranges of sulfur concentration (Rückriemen et al. 2015). With cooling, the crystallization mechanisms can evolve further, depending on the bulk sulfur content (see Fig. 14).

The implications of the Fe snow regime for the core dynamics and magnetic field evolution are controversial. Hauck et al. (2006) proposed that the sinking iron particles may cause motions within the fluid of the stable snow zone and, thereby, provide the driving force for the magnetic field of Ganymede. By applying the magnetic field strength scaling law of Christensen and Aubert (2006), they found surface magnetic field strengths between 600 and $1600 \mathrm{nT}$. However, Hauck et al. (2006) failed to explain why particle settling in a stably stratified fluid would cause the large-scale fluid motions that are necessary for a dynamo (Christensen and Wicht 2007). Zhan and Schubert (2012) used a magneto-hydrodynamic dynamo model and assumed that the sinking of iron crystals in the snow zone would be equivalent to internally heated convection. They found multipolar solutions for the magnetic field, at variance with the observed strong dipolarity of the field (Kivelson et al. 2002). Their main assumption that $\mathrm{Fe}$ snow resembles internally heated convection is questionable, because they did not model the particular flow. These authors suggested that dipole-dominated magnetic fields are only possible for FeS floating dynamos and inner-core growth, the latter implying a low concentration of sulfur.

Zhan and Schubert's (2012) conclusions are consistent with the thermal and magnetic field evolution models of Bland et al. (2008). The former authors suggested that the power requirement for dynamo action can only be satisfied if the sulfur mass fraction in Ganymede's core is either very low ( $<3 \mathrm{wt} . \%$, with freezing starting at the core center) or very high ( $>22.5$ wt.\%; i.e., solidification of FeS deep within the core). They further argued that the conditions for magnetic field generation cannot be met in the iron snow regime, because the latent heat released by the solidification of iron would readily be removed by the mantle above and thus be unavailable to power the dynamo. However, the assumption of latent heat being released close to the CMB is only correct initially, when the 


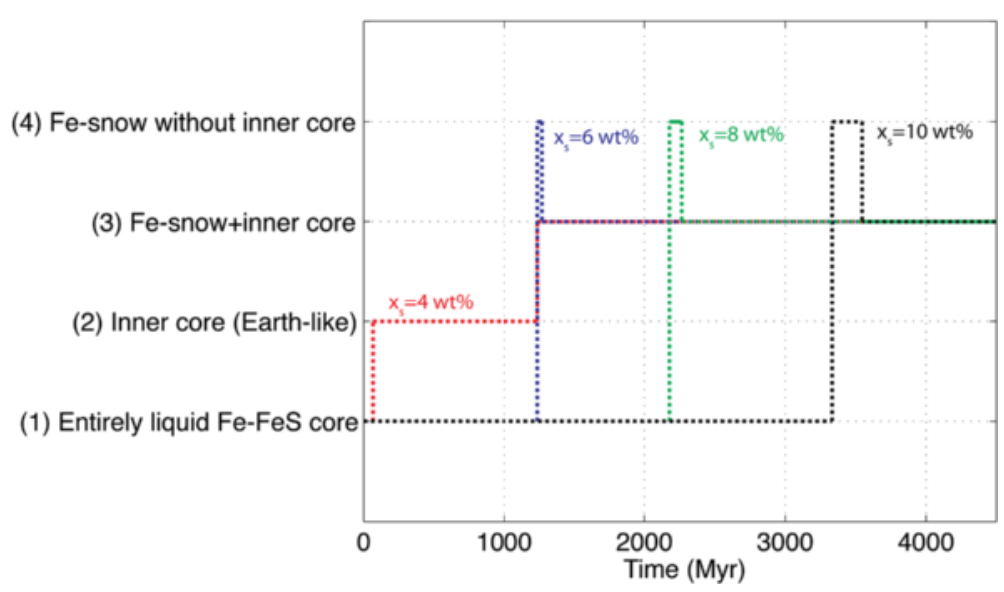

Fig. 14 Evolution of crystallization regimes in Ganymede's core. Evolution of the core state for four bulk core sulfur contents and $\mathrm{Cl}$ chondritic heat production. The model with 4 wt.\% sulfur passes through a period with an Earth-like core evolution prior to beginning precipitation of Fe snow. With increasing sulfur content, crystallization starts later because of the lower melting temperature and commences directly with Fe snow until a solid inner core starts to grow (after Hauck et al. 2006)

snow zone starts to grow. For continuous cooling, the snow zone extends into deeper core regions, thereby triggering the release of latent heat in the deeper core as well.

In a recent study, Christensen (2015) proposed that the deeper, entirely fluid core below the zone snow could be the locale of the dynamo. Compositional convection would be driven by the sinking and remelting of iron crystals in the lower core region underlying an electrically conducting snow zone with a strongly stabilizing density gradient. For plausible values of the buoyancy flux from Rückriemen et al. (2015) and an upper stable layer that is thinner than the fluid layer below, the model can reproduce Ganymede's observed dipole. Such a dynamo would be restricted in its lifetime by the time the snow zone takes to grow through the core. Rückriemen et al. (2015) found values of 320-800 Myr, depending mainly on the initial core sulfur content and the heat flow from the core. To best explain the present magnetic field with such a model, high sulfur concentrations (but lower than the eutectic concentration) were favored. The dynamo would then start late in the evolution and could easily last to the present day. Moreover, the model would predict the absence of a solid inner core.

Magnetic field generation for a core composition on the sulfur-rich side of the eutectic has been studied less often. FeS floating, where FeS crystals form first in the core center and rise, is considered a viable mechanism for dynamo action in Ganymede (Hauck et al. 2006; Bland et al. 2008; Zhan and Schubert 2012). Thermal evolution models showed that the power requirements for a dynamo can be met (Bland et al. 2008) and magneto-hydrodynamic models showed that dipole-dominated magnetic fields are possible with this specific freezing mechanism, since buoyancy sources are located at the bottom of the convective zone, similar to the Earth-like case (Zhan and Schubert 2012). However, at Ganymede's core pressures, FeS crystallization at the $\mathrm{CMB}$ or in the core is more likely (see Fig. 2) than in the center, and a solid outer-core layer would grow inward, similar to the Earth's inner-core growth but in reverse (see Fig. 1c, d). Such a dynamo could be long lasting (at least longer than the dynamo in the Fe snow regime), because compositional convection in a cooling Ganymede would only stop when the eutectic composition is reached in the liquid inner core. However, whether enough power for dynamo action can be generated with this scenario still needs to be tested.

\section{Conclusions}

Our perception of the cores of terrestrial planets and moons and their crystallization have changed substantially during the past few years. Improved Fe-FeS phase diagrams and melting relations have motivated novel models of core dynamics and dynamos, in particular for planetary bodies with masses significantly smaller than the Earth's. The most important findings are that the melting temperature at the eutectic decreases with increasing pressure up to $14 \mathrm{GPa}$ and that the eutectic composition decreases with increasing pressure up to about $60 \mathrm{GPa}$ (see Fig. 3). Both effects imply Fe crystallization at the $\mathrm{CMB}$ and iron snow fall for wide ranges of sulfur concentrations if $\mathrm{d} T / \mathrm{d} P_{\text {ad }}>\mathrm{d} T / \mathrm{d} P_{\text {melt }}$. Iron snow can provide a viable dynamo mechanism for the Moon, Mercury, and Ganymede and would even be likely for Martian core pressures up to $40 \mathrm{GPa}$, suggesting that dynamo generation may occur in the future through this mechanism. In iron-rich cores that comprise a large pressure range, as for Mercury, even several zones of iron snow can emerge. The lunar case is less clear, however, since Fe may start to 
crystallize in the center for a sulfur concentration below about 8 wt.\%, while for higher sulfur contents, iron snow would be the dominant mechanism.

Crystallization of $\mathrm{FeS}$ for sulfur-rich compositions is a less well-developed scenario, but it would also differ from the classical Earth case of solid inner-core growth from the center. Here, FeS would precipitate either at the CMB, in the core, or at the core center, depending on the sulfur concentration and the temperature profile. The situation on the sulfur-rich side of the eutectic can be even more complex, because the solid phase depends on pressure and may change to $\mathrm{Fe}_{3} \mathrm{~S}_{2}$ or $\mathrm{Fe}_{3} \mathrm{~S}$, crystal phases that differ in density from FeS. In summary, a rich variety of crystallization scenarios and dynamos have become apparent and it has become clear that the Earth-like dynamo is probably not typical. While we observe this for the comparatively simple $\mathrm{Fe}-\mathrm{FeS}$ system, we note that more realistic models incorporating other light elements should be even more varied and complex.

The models we have reviewed in this paper further show that better knowledge of the adiabatic temperature gradient and the adiabatic heat flux is required. First, the relation between the slopes of the adiabatic temperature and the melting temperature as a function of pressure determines the crystallization process; i.e., whether the first crystals form at the $\mathrm{CMB}$, in the center, or somewhere in the core. Note, however, that it is not obvious that the core temperature must vary along an adiabat at the time of first crystal formation. For thermal evolution models, we typically attain a subadiabatic core heat flux after a few hundred million years of evolution and prior to crystallization. The core is then likely thermally stable, exhibiting a conductive core temperature profile. Second, there is an inverse correlation between the heat flux along the adiabat and the lifetime of the dynamo. In the contemporary literature, we find differences in the dynamo lifetime for either a thermal or compositional dynamo from $100 \mathrm{Ma}$ to several billion years, depending on the parameters adopted for the thermal conductivity and thermal expansivity and, thus, for the adiabatic heat flux.

In conclusion, the crystallization processes in the cores of the terrestrial planets and moons are diverse and imply diversity in the mechanisms and efficiency of dynamo action. To improve our understanding, better constraints on the thermal properties, the melting relations, as well as the compositions of the cores are required through experimental work on phase diagrams and transport properties, numerical modeling, and space mission data to constrain the core compositions. Open questions to be answered are manifold. A few that result immediately from the present discussion are as follows: Can a dynamo be generated in the stable iron snow zone or only in the fluid core below? Is the concept of thermochemical equilibrium for iron snow appropriate, and what are the consequences if iron does not remelt during descent? What is the composition of the core of the terrestrial planets and moons and how does the composition alter the thermal properties and the melting temperatures?

\section{Abbreviations}

CMB: core-mantle boundary; LHB: late heavy bombardment.

\section{Competing interests}

The authors declare that they have no competing interests.

\section{Authors' contributions}

DB proposed the topic. TS and TR collaborated with the corresponding author on the composition of the manuscript. All authors read and approved the final manuscript.

\section{Authors' information}

All authors are from the DLR (German Aerospace Agency), Institute of Planetary Research, Rutherfordstrasse 2,12489 Berlin, Germany. DB is the head of the "Planetary Physics" department, TR is pursuing her Ph.D. degree in the "Planetary Physics" department, and TS is the director of the Institute of Planetary Research.

\section{Acknowledgements}

We thank Sabine Stanley and an anonymous reviewer for excellent reviews and constructive comments. This work has been supported by the DFG (German Research Foundation) as part of the priority program "Planetary magnetism," SPP 1488.

Received: 20 February 2015 Accepted: 28 October 2015

Published online: 16 November 2015

\section{References}

Acuña MH, Connerney JEP, Ness NF, Lin RP, Mitchell D, Carlson CW, et al. Magnetic field and plasma observations at Mars: initial results of the Mars Global Surveyor Mission. Science. 1998;279:1676-80.

Acuña MH, Connerney JEP, Ness NF, Lin RP, Mitchell D, Carlson CW, et al. Global distribution of crustal magnetism discovered by the Mars Global Surveyor MAG/ER Experiment. Science. 1999;284:790-3.

Acuña MH, Connerney JEP, Wasilewski P, Lin RP, Mitchell D, Anderson KA, et al. Magnetic field of Mars: summary of results from the aerobraking and mapping orbits. J Geophys Res. 2001;106:23403-18.

Alfè D, Gillan MJ, Price GD. Complementary approaches to the ab initio calculation of melting properties. J Chem Phys. 2002;116:6170-7.

Amit $\mathrm{H}$, Christensen UR, Langlais B. The influence of degree-1 mantle heterogeneity on the past dynamo of Mars. Phys Earth Planet Inter. 2011;189:63-79.

Anderson JD, Colombo G, Esposito PB, Lau EL, Trager GB. The mass, gravity field, and ephemeris of Mercury. Icarus. 1987; 71:337-349.Anderson JD, Jurgens RF, Lau EL, Slade III MA, Schubert G. Shape and orientation of Mercury from radar ranging data. Icarus. 1996;124:690-7.

Anderson JD, Jacobson RA, Elrath TP, Moore WB, Schubert G, Thomas PC. Shape, mean radius, gravity field, and interior structure of Callisto. Nature. 2001;384:157-61.

Anderson BJ, Johnson CL, Korth H, Purucker ME, Winslow RM, Slavin JA, et al. The global magnetic field of Mercury from MESSENGER orbital observations. Science. 2011;333:1859-62.

Anderson BJ, Johnson CL, Korth H, Winslow RM, Borovsky JE, Purucker ME, et al. Low-degree structure in Mercury's planetary magnetic field. J Geophys Res. 2012. doi:10.1029/2012JE004159.

Arkani-Hamed J, Olson P. Giant impact stratification of the martian core. Geophys Res Lett. 2010. doi:10.1029/2009GL041417.

Assael MJ, Kakosimos K, Banish RM, Brillo J, Egry I, Brooks R, et al. Reference data for the density and viscosity of liquid aluminum and iron. J Phys Chem Ref Data. 2006;35:285-300.

Aubert J, Labrosse S, Poitou C. Modelling the palaeo-evolution of the geodynamo. Geophys J Int. 2009;179:1414-28.

Badro J, Fiquet G, Guyot F, Gregoryanz E, Occelli F, Antonangeli D, et al. Effect of light elements on the sound velocities in solid iron: implications for the composition of Earth's core. Earth Planet Sci Lett. 2007;254:233-8. 
Badro J, Côté AS, Brodholt JP. A seismologically consistent compositional model of Earth's core. Proc Natl Acad Sci. 2014;111:7542-5.

Bertka CM, Fei Y. Mineralogy of the Martian interior up to core-mantle boundary pressures. J Geophys Res. 1997;102:5251-64.

Bland MT, Showman AP, Tobie G. The production of Ganymede's magnetic field. Icarus. 2008;198:384-399.

Bleil U, Petersen N. Variations in magnetization intensity and low-temperature titanomagnetite oxidation of ocean floor basalts. Nature. 1983;301:384-8.

Boehler R. Melting of the Fe FeO and the Fe FeS systems at high pressure: constraints on core temperatures. Earth Planet Sci Lett. 1992;111:217-27.

Boehler R. Temperatures in the Earth's core from melting-point measurements of iron at high static pressures. Nature. 1993;363:534-6.

Boehler R. Fe-FeS eutectic temperatures to 620 kbar. Phys Earth Planet Inter. 1996:96:181-6.

Boehler R, Bargen NV, Chopelas A. Melting, thermal expansion, and phase transitions of iron at high pressures. J Geophys Res. 1990;95:21731-6.

Braginsky SI. Magnetohydrodynamics of the Earth core. Geomagn Aeron. 1964:4:698-712.

Breuer D, Moore WB. Dynamics and thermal history of the terrestrial planets, the Moon, and Io. In: Spohn T, Schubert G, editors. Treatise on Geophysics, vol. 10. 2nd ed. Oxford: Elsevier; 2015. p. 255-305.

Breuer D, Spohn T. Cooling of the Earth, Urey ratios, and the problem of potassium in the core. Geophys Res Lett. 1993;20:1655-8.

Breuer D, Spohn T. Early plate tectonics versus single-plate tectonics: evidence from the magnetic field history and crust evolution. J Geophys Res. 2003;108:5072. doi:10.1029/20002JE001999.

Breuer D, Spohn T. Viscosity of the Martian mantle and its initial temperature: constraints from crust formation history and the evolution of the magnetic field. Planet Sci Lett. 2006;54:153-69.

Breuer D, Hauck SA, Buske M, Pauer M, Spohn T. Interior evolution of Mercury. Space Sci Rev. 2007;132:229-60.

Breuer D, Labrosse S, Spohn T. Thermal evolution and magnetic field generation in terrestrial planets and satellites. Space Sci Rev. 2010;152:449-500.

Buffett BA. Estimates of heat flow in the deep mantle based on the power requirements for the geodynamo. Geophys Res Lett. 2002. doi:10.1029/ 2001GL014649.

Buono AS, Walker D. The Fe-rich liquidus in the Fe-FeS system from 1 bar to 10 GPa. Geochim Cosmochim Acta. 2011:75:2072-87.

Busse FH. Generation of planetary magnetism by convection. Phys Earth Planet Inter. 1976;12:350-8.

Byrne PK, Klimczak C, Şengör AC, Solomon SC, Watters TR, Hauck SA. Mercury/'s global contraction much greater than earlier estimates. Nat Geosci. 2014;7:301-7.

Cameron AGW, Fegley Jr B, Benz W, Slattery WL. The strange density of Mercury: theoretical considerations. In: Vilas F, Chapman CR, Matthews MS, editors. Mercury. Tucson: Univ. Arizona Press; 1988. p. 692-708.

Campbell AJ, Seagle CT, Heinz DL, Shen G, Prakapenka VB. Partial melting in the iron-sulfur system at high pressure: a synchrotron X-ray diffraction study. Phys Earth Planet Inter. 2007;162:119-28.

Cao H, Aurnou JM, Wicht J, Dietrich W, Soderlund KM, Russell CT. A dynamo explanation for Mercury's anomalous magnetic field. Geophys Res Lett. 2014:41:4127-34

Chabot NL, Campbell AJ, McDonough WF, Draper DS, Agee CB, Humayun M, et al. The Fe-C system at 5GPa and implications for Earth's core. Geochim Cosmochim Acta. 2008:72:4146-58.

Chabot NL, Wollack EA, Klima RL, Minitti ME. Experimental constraints on Mercury's core composition. Earth Planet Sci Lett. 2014;390:199-208.

Chen B, Li J, Hauck II SA. Non-ideal liquidus curve in the Fe-S system and Mercury's snowing core. Geophys Res Lett. 2008;35:L07201. doi:10.1029/2008GL033311.

Christensen UR. A deep dynamo generating Mercury's magnetic field. Nature. 2006:444:1056-8.

Christensen UR. Dynamo scaling laws and applications to the planets. Space Sci Rev. 2010;152:565-90.

Christensen UR. Iron snow dynamo models for Ganymede. Icarus. 2015;247:248-59.

Christensen UR, Aubert J. Scaling properties of convection-driven dynamos in rotating spherical shells and application to planetary magnetic fields. Geophys J Int. 2006;166:97-114.

Christensen UR, Tilgner A. Power requirement of the geodynamo from ohmic losses in numerical and laboratory dynamos. Nature. 2004;429:169-71.
Christensen UR, Wicht J. Numerical dynamo simulations. In: Schubert G, editor Core dynamics, Treatise on Geophysics, vol. 10. Oxford: Elsevier; 2007. p. 245-82.

Christensen UR, Wicht J. Models of magnetic field generation in partly stable planetary cores: applications to Mercury and Saturn. Icarus. 2008;196:16-34.

Chudinovskikh L, Boehler R. Eutectic melting in the system Fe-S to 44 GPa. Earth Planet Sci Lett. 2007;257:97-103.

Cisowski SM, Fuller M. Lunar paleointensities via the IRMs normalization method and the early magnetic history of the moon. In: Hartmann WK, Phillips RJ, Taylor GJ, editors. Origin of the Moon. Tucson: Univ. Arizona Press; 1986. p. $411-24$

Collinson DW. Magnetic properties of Martian meteorites: implications for an ancient Martian magnetic field. Meteoritics. 1997;803:32-6.

Connerney JEP. Planetary magnetism. In: Spohn T, Schubert G, editors. Treatise on Geophysics, 2nd ed, Vol. 10, Planets and Moons. Amsterdam: Elsevier; 2015.

Connerney JEP, Ness NF. Mercuny's magnetic field and interior. In: Vilas F, Chapman CR, Matthews MS, editors. Mercury. Tucson: Univ. of Arizona Press; 1988. p. 494-513.

Connerney JEP, Acuña MH, Wasilewski $P$, Ness NF, Rème $H$, Mazelle $C$, et al. Magnetic lineations in the ancient crust of Mars. Science. 1999;284:794-8.

Connerney JEP, Acuna MH, Ness NF, Spohn T, Schubert G. Mars crustal magnetism. Space Sci Rev. 2004;111:1-32.

Curtis SA, Ness NF. Magnetostrophic balance in planetary dynamos: predictions for Neptune's magnetosphere. J Geophys Res. 1986;91:11003-8.

de Koker N, Steinle-Neumann G, Vlček V. Electrical resistivity and thermal conductivity of liquid Fe alloys at high P and T, and heat flux in Earth's core. Proc Natl Acad Sci U S A. 2012;109:4070-3.

Deng L, Seagle C, Fei Y, Shahar A. High pressure and temperature electrical resistivity of iron and implications for planetary cores. Geophys Res Lett. 2013:40:33-7.

Dietrich W, Wicht J. A hemispherical dynamo model: implications for the Martian crustal magnetization. Phys Earth Planet Inter. 2013;217:10-21.

Dreibus G, Wänke H. Mars: a volatile rich planet. meteoritics. 1985;20:367-82.

Dumberry M, Rivoldini A. Mercury's inner core size and core-crystallization regime. Icarus. 2015;248:254-68.

Dwyer CA, Stevenson DJ, Nimmo F. A long-lived lunar dynamo driven by continuous mechanical stirring. Nature. 2011;479:212-4.

Evans AJ, Zuber MT, Weiss BP, Tikoo SM. A wet, heterogeneous lunar interior: lower mantle and core dynamo evolution. J Geophys Res. 2014;119:1061-77.

Fegley Jr B, Cameron AGW. A vaporization model for iron/silicate fractionation in the Mercury protoplanet. Earth Planet Sci Lett. 1987;82:207-22.

Fei Y, Bertka C. The interior of Mars. Science. 2005:308:1120-1.

Fei Y, Bertka CM, Finger LW. High-pressure iron-sulfur compound, $\mathrm{Fe}_{3} \mathrm{~S}_{2}$, and melting relations in the Fe-FeS system. Science. 1997;275:1621-3.

Fei Y, Li J, Bertka CM, Prewitt CT. Structure type and bulk modulus of $\mathrm{Fe}_{3} \mathrm{~S}$, a new iron-sulfur compound. Am Minerol. 2000;85:1830-3.

Fuller M, Cisowski SM. Lunar paleomagnetism. Geomagn. 1987;2:307-455.

Gaidos E, Conrad CP, Manga M, Hernlund J. Thermodynamic limits on magnetodynamos in rocky exoplanets. Astrophys J. 2010;718:596-609.

Garcia R, Gagnepain-Beyneix J, Chevrot S, Lognonne P. Very preliminary reference Moon model. Phys Earth Planet Inter. 2011;188:96-113.

Garrick-Bethell I, Weiss BP, Shuster DL, Buz J. Early lunar magnetism. Science. 2009;323:356-9.

Gessmann CK, Wood BJ. Potassium in the Earth's core? Earth planet. Sci Lett. 2002:200:63-78

Gomi H, Ohta K, Hirose K, Labrosse S, Caracas R, Verstraete MJ, et al. The high conductivity of iron and thermal evolution of the Earth's core. Phys Earth Planet Inter. 2013;224:88-103.

Grott M, Breuer D, Laneuville M. Thermo-chemical evolution and global contraction of Mercury. Earth Planet Sci Lett. 2011;307:135-46.

Hauck SA, Phillips RJ. Thermal and crustal evolution of Mars. J Geophys Res. 2002. doi:10.1029/2001JE001801.

Hauck SA, Dombard AJ, Phillips RJ, Solomon SC. Internal and tectonic evolution of Mercury. Earth Planet Sci Lett. 2004;222:713-28.

Hauck SA, Aurnou JM, Dombard AJ. Sulfur's impact on core evolution and magnetic field generation on Ganymede. J Geophys Res. 2006. doi:10.1029/2005JE002557.

Hauck II SA, Margot J-L, Solomon SC, Lemoine FG, Mazarico E, Peale SJ, et al. The curious case of Mercury's internal structure. J Geophys Res. 2013;118:1303-22.

Heimpel MH, Aurnou JM, Al-Shamali FM, Gomez Perez N. A numerical study of dynamo action as function of spherical shell geometry. Earth Planet Sci Lett. 2005;236:542-57.

Hide R. Comments on the Moon's magnetism. Moon. 1972;4:39. 
Hirose K, Labrosse S, Hernlund J. Composition and state of the core. Annu Rev Earth Planet Sci. 2013:41:657-91.

Hixson RS, Winkler MA, Hodgdon ML. Sound speed and thermophysical properties of liquid iron and nickel. Phys Rev B. 1990;42:6485-91.

Hood LL, Huang Z. Formation of magnetic anomalies antipodal to lunar impact basins: two dimensional model calculations. J Geophys Res. 1991;96:9837-46.

Hood LL, Vickery A. Magnetic field amplification and generation in hypervelocity meteorid impacts with application to lunar paleomagnetism. J Geophys Res. 1984;89:C211-23.

Hood LL, Mitchell DL, Lin RP, Acuna MH, Binder AB. Initial measurements of the lunar induced magnetic dipole moment using Lunar Prospector magnetometer data. Geophys Res Lett. 1999;106:27825-39.

Hood LL, Zakharian A, Halekas J, Mitchell DL, Lin RP, Acuna MH. Initial mapping and interpretation of lunar crustal magnetic anomalies using Lunar Prospector magnetometer data. J Geophys Res. 2001;106:27825-39.

Hood LL, Harrison KP, Langlais B, Lillis RJ, Poulet F, Williams DA. Magnetic anomalies near Apollinaris Patera and the Medusae Fossae Formation in Lucus Planum, Mars. Icarus. 2010. doi:10.1016/j.icarus.2010.01.009.

less L, Rappaport NJ, Jacobson RA, Racioppa P, Stevenson DJ, Tortora P, et al. Gravity field, shape, and moment of inertia of Titan. Science. 2010;327:1367-9.

Johnson CL, Purucker ME, Korth H, Anderson BJ, Winslow RM, Al Asad MM, et al. MESSENGER observations of Mercury's magnetic field structure. J Geophys Res. 2012. doi:10.1029/2012JE004217.

Johnson CL, Phillips RJ, Purucker ME, Anderson BJ, Byrne PK, Denevi BW, et al. Low-altitude magnetic field measurements by MESSENGER reveal Mercury's ancient crustal field. Science. 2015;348:892-5.

Kaiura GH, Toguri JM. Densities of the molten FeS, FeS-Cu2S and Fe-S-O systems-utilizing a bottom-balance Archimedean technique. Can Metall Q. 1979;18:155-64.

Kandpal D, Gupta BRK. Analysis of thermal expansivity of iron (Fe) metal at ultra high temperature and pressure. Pramana. 2007;68:129-34.

Kimura J, Nakagawa T, Kurita K. Size and compositional constraints of Ganymede's metallic core for driving an active dynamo. Icarus. 2009:202:216-24.

Kivelson MG, Khurana KK, Russell CT, Walker RJ, Warnecke J, Coroniti FV, et al. Discovery of Ganymede's magnetic field by the Galileo spacecraft. Nature. 1996;384:537-41

Kivelson MG, Khurana KK, Volwerk M. The permanent and inductive magnetic moments of Ganymede. Icarus. 2002;157:507-22.

Konopliv AS, Binder AB, Hood LL, Kucinskas AB, Sjogren WL, Williams JG. Improved gravity field of the Moon from Lunar Prospector. Science. 1998;281:1476-80.

Konrad W, Spohn T. Thermal history of the Moon: implications for an early core dynamo and post-accretional magmatism. Adv Space Rev. 1997;19:1511-21.

Kuwayama Y, Hirose K. Phase relations in the system Fe-FeSi at $21 \mathrm{GPa}$. Am Minerol. 2004;89:273-6.

Labrosse S. Thermal and magnetic evolution of the Earth's core. Phys Earth Planet Inter. 2003;140:127-43.

Laneuville M, Wieczorek MA, Breuer D, Aubert J, Morard G, Rückriemen T. A longlived lunar dynamo powered by core crystallization. Earth Planet Sci Lett. 2014;401:251-60

Langlais B, Purucker ME, Mandea M. Crustal magnetic field of Mars. J Geophys Res. 2004;109:E02008. doi:10.1029/2003JE002048.

Le Bars M, Wieczorek MA, Karatekin O, Cebron D, Laneuville M. An impact-driven dynamo for the early Moon. Nature. 2011;479:215-8.

Lee KK, Steinle-Neumann G, Jeanloz R. Ab-initio high-pressure alloying of iron and potassium: implications for the Earth's core. Geophys Res Lett. 2004;31:L11603. doi:10.1029/2004GL019839.

Lewis JS. Satellites of the outer planets: their physical and chemical nature. Icarus. $1971 ; 15: 174-85$

Lewis JS. Chemistry of the planets. Annu Rev Phys Chem. 1973;24:339-51.

Li J, Fei Y, Mao HK, Hirose K, Shieh SR. Sulfur in the Earth's inner core. Earth Planet Sci Lett. 2001;193:509-14.

Lodders K, Fegley B. The planetary scientist's companion. New York: Oxford University Press; 1998.

Malavergne V, Tarrida M, Combes R, Bureau H, Jones J, Schwandt C. New highpressure and high-temperature metal/silicate partitioning of $\mathrm{U}$ and $\mathrm{Pb}$ : Implications for the cores of the Earth and Mars. Geochim Cosmochim Acta. 2007;71:2635-55
Malavergne V, Toplis MJ, Berthet S, Jones J. Highly reducing conditions during core formation on Mercury: implications for internal structure and the origin of a magnetic field. Icarus. 2010;206:199-209.

Manglik A, Wicht J, Christensen UR. A dynamo model with double diffusive convection for Mercury's core. Earth Planet Sci Lett. 2010;289:619-28.

Margot JL, Peale SJ, Jurgens RF, Slade MA, Holin IV. Large longitude libration of Mercury reveals a molten core. Science. 2007;316:710-4.

Margot JL, Peale SJ, Solomon SC, Hauck SA, Ghigo FD, Jurgens RF, et al. Mercury's moment of inertia from spin and gravity data. J Geophys Res. 2012. doi:10.1029/2012JE004161.

McCammon CA, Ringwood AE, Jackson I. Thermodynamic of the system Fe-FeO$\mathrm{MgO}$ at high pressure and temperature and a model for the formation of the Earth's core. Geophys J Roy Astron Soc. 1983;72:577-95.

McCubbin FM, Riner MA, Vander Kaaden KE, Burkemper LK. Is Mercury a volatilerich planet? Geophys Res Lett. 2012;39:L09202. doi:10.1029/2012GL051711.

McDonough WF. Compositional model for the Earth's core. In: Carlson RW, Holland H, Turekian K, editors. Treatise on Geochemistry, vol. 3. 2nd ed Amsterdam: Elsevier; 2014. p. 559-77.

McSween Jr HY. SNC meteorites: clues to Martian petrologic evolution? Rev Geophys. 1985:23:391-416

Michel N, Forni O. Mars mantle convection: influence of phase transitions with core cooling. Planet Space Sci. 2011;59:741-8.

Mitchell DL, Lin RP, Rème $H$, Acuña MH, Cloutier PA, Ness NF. Crystal magnetospheres observed in the Martian night hemisphere. Am. Astronomical Society, DPS Meeting \#31, abstracts \#59.04, Bulletin of the American Astronomical Society. 1999:31;1584.

Mitchell DL, Lin RP, Mazelle C, Rème H, Cloutier PA, Connerney JEP, et al. Probing Mars' crustal magnetic field and ionosphere with the MGS Electron Reflectometer. J Geophys Res. 2001;106:23419-28.

Mohit PS, Arkani-Hamed J. Impact demagnetization of the Martian crust. Icarus. 2004;168:305-17

Monteux J, Jellinek AM, Johnson CL. Dynamics of core merging after a megaimpact with applications to Mars' early dynamo. Icarus. 2013;226:20-32.

Morard G, Katsura T. Pressure-temperature cartography of Fe-S-Si immiscible system. Geochim Cosmochim Acta. 2010;74:3659-67.

Morard G, Sanloup C, Fiquet G, Mezouar M, Rey N, Poloni R, et al. Structure of eutectic Fe-FeS melts to pressures up to $17 \mathrm{GPa}$ : implications for planetary cores. Earth Planet Sci Lett. 2007;263:128-39.

Morard G, Andrault D, Guignot N, Sanloup C, Mezouar M, Petitgirard S, et al. In situ determination of Fe-Fe3S phase diagram and liquid structural properties up to 65 GPa. Earth Planet Sci Lett. 2008:272:620-62.

Morgan JW, Anders E. Chemical composition of earth, Venus, and Mercury. Proc Natl Acad Sci U S A. 1980;77:6973-7.

Morschhauser A, Lesur V, Grott M. A spherical harmonic model of the lithospheric magnetic field of Mars. J Geophys Res. 2014;119:1162-88.

Murthy VR. Early differentiation of the Earth and the problem of mantle siderophile elements: a new approach. Science. 1991;253:303-6.

Murthy VR, Van Westrenen W, Fei Y. Experimental evidence that potassium is a substantial radioactive heat source in planetary cores. Nature. 2003;423:163-5.

Naldrett AJ. A portion of the system Fe-S-O between 900 and $1080 \mathrm{C}$ and its application to sulfide ore magmas. J Petrol. 1969;10:171-201.

Nasch PM, Steinemann SG. Density and thermal expansion of molten manganese, iron, nickel, copper, aluminum and tin by means of the gamma-ray attenuation technique. Phys Chem Liq. 1995:29:43-58.

Ness NF, Behannon KW, Lepping RP, Schatten KH, Whang YC. Magnetic field observations near Mercury: preliminary results from Mariner 10. Science. 1974;185:151-60.

Ness NF, Behannon KW, Lepping RP, Whang YC. Magnetic field of Mercury. J Geophys Res. 1975;80:2708-16.

Ness NF, Behannon KW, Lepping RP, Whang YC. Observations of Mercury's magnetic field. Icarus. 1976;28:479-88.

Ness NF, Acuña MH, Connerney J, Wasilewski P, Mazelle C, Sauvaud J, et al. MGS magnetic fields and electron reflectometer investigation: discovery of paleomagnetic fields due to crustal remanence. Adv Space Res. 1999;23:1879-86.

Nimmo F. Energetics of the core. In: Schubert G, editor. Treatise on Geophysics, vol. 8. 1st ed. Amsterdam: Elsevier; 2007. p. 31-65.

Nimmo F. Thermal and compositional evolution of the core. In: Schubert G, editor. Treatise on Geophysics, vol. 8. 2nd ed. Amsterdam: Elsevier; 2015. p. 201-19. 
Nimmo F, Stevenson D. Influence of early plate tectonics on the thermal evolution and magnetic field of Mars. J Geophys Res. 2000;105:11969-79.

Nittler LR, Starr RD, Weider SZ, McCoy TJ, Boynton WV, Ebel DS, et al. The majorelement composition of Mercury's surface from MESSENGER X-ray spectrometry. Science. 2011;333:1847-950.

Ohta K, Suehiro S, Hirose K, Ohishi, Y. The electrical resistivity of iron alloys at Earth's core conditions. Goldschmidt 2015 Conf. Abstr. Book, 2326. 2015.

Olson P, Christensen UR. Dipole moment scaling for convection-driven planetary dynamos. Earth Planet Sci Lett. 2006;250:561-71.

Peale SJ. Inferences from the dynamical history of Mercury's rotation. Icarus. 1976;28:459-67.

Peplowski PN, Evans LG, Hauck SA, McCoy TJ, Boynton WV, Gillis-Davis JJ, et al. Radioactive elements on Mercury's surface from MESSENGER: implications for the planet's formation and evolution. Science. 2011;333:1850-2.

Peplowski PN, Lawrence DJ, Rhodes EA, Sprague AL, McCoy TJ, Denevi BW, et al. Variations in the abundances of potassium and thorium on the surface of Mercury: results from the MESSENGER Gamma-Ray Spectrometer. J Geophys Res. 2012;117:EO0L04 doi:10.1029/2012JE004141

Pozzo M, Davies C, Gubbins D, Alfe D. Thermal and electrical conductivity of iron at Earth's core conditions. Nature. 2012:485:355-9.

Rai N, van Westrenen W. Core-mantle differentiation in Mars. J Geophys Res. 2013;118:1195-203.

Reese CC, Solomatov VS. Early martian dynamo generation due to giant impacts Icarus. 2010;207:82-97.

Ringwood AE. Composition of the core and implications for the origin of the Earth. Geochem J. 1977;11:111-35.

Rivoldini A, Van Hoolst T. The interior structure of Mercury constrained by the low-degree gravity field and the rotation of Mercury. Earth Planet Sci Lett. 2013;377:62-72

Roberts PH, Jones CA, Calderwood AR. Energy fluxes and ohmic dissipation in the Earth's core. Earth's core and lower mantle. In: Jones C, Soward AM, Zhang K, editors. Book series the fluid mechanics of astrophysics and geophysics. Vol. 11. London: Taylor \& Francis; 2003. p. 100-129.

Roberts JH, Lillis RJ, Manga M. Giant impacts on early Mars and the cessation of the Martian dynamo. J Geophys Res. 2009;114:E04009. doi:10.1029/2008JE003287

Rochette P, Lorand J-P, Fillion G, Sautter V. Pyrrhotite and the remanent magnetization of SNC meteorites: a changing perspective on Martian magnetism. Earth Planet Sci Lett. 2001;190:1-12.

Rochette P, Fillion G, Ballou R, Brunet F, Ouladdiaf B, Hood L. High pressure magnetic transition in pyrrhotite and impact demagnetization on Mars. Geophys Res Lett 2003:30. doi:10.1029/2003GL017359.

Rückriemen T, Breuer D, Spohn T. The Fe-snow regime in Ganymede's core: a deep seated dynamo below a stable snow zone. J Geophys Res. 2015;120:1095-118.

Russell CT, Baker DN, Slavin JA. The magnetosphere of Mercury. In: Vilas F, Chapman CR, Matthews MS, editors. Mercury. Tucson: Univ. of Arizona Press; 1988. p. 514-61.

Sanloup C, Fei Y. Closure of the Fe-S-Si liquid miscibility gap at high pressure. Phys Earth Planet Inter. 2004;147:57-65

Sanloup C, Guyot F, Gillet P, Fiquet G, Mezouar M, Martinez I. Density measurements of liquid Fe-S alloys at high-pressure. Geophys Res Lett. 2000:27:811-4

Scheinberg A, Soderlund KM, Schubert G. Magnetic field generation in the lunar core: the role of inner core growth. Icarus. 2015;254:62-71.

Schubert G, Spohn T. Thermal history of Mars and the sulfur content of its core. J Geophys Res. 1990:95:14095-104.

Schubert G, Ross MN, Stevenson DJ, Spohn T. Mercury's thermal history and the generation of its magnetic field. In: Vilas F, Chapman CR, Matthews MS, editors. Mercury'. Tucson: Univ. of Arizona Press; 1988. p. 514-61.

Schubert G, Zhang K, Kivelson MG, Anderson JD. The magnetic field and internal structure of Ganymede. Nature. 1996;384:544-5.

Schubert G, Russell CT, Moore WB. Timing of the Martian dynamo. Nature. 2000:408:666-7.

Schubert G, Anderson JD, Spohn T, McKinnon WB. Interior composition, structure and dynamics of the Galilean satellites. In: Bagenal F, Dowling T, McKinnon WB, editors. Jupiter: the planet, satellites and magnetosphere. Cambridge: Cambridge Uni. Press; 2004. p. 281-306.

Scott HP, Williams Q, Ryerson FJ. Experimental constraints on the chemical evolution of large icy satellites. Earth Planet Sci Lett. 2002;203:399-412.
Shea EK, Weiss BP, Cassata WS, Shuster DL, Tikoo SM, Gattacceca J, et al. A long-lived lunar core dynamo. Science. 2012;335:453-6.

Shen G, Mao HK, Hemley RJ, Duffy TS, Rivers ML. Melting and crystal structure of iron at high pressures and temperatures. Geophys Res Lett. 1998;25:373-6

Shimizu H, Matsushima M, Takahashi F, Shibuya H, Tsunakawa H. Constraint on the lunar core size from electromagnetic sounding based on magnetic field observations by an orbiting satellite. Icarus. 2013;222:32-43.

Siebert J, Malavergne V, Guyot F, Combes R, Martinez I. The behaviour of sulphur in metal-silicate core segregation experiments under reducing conditions. Phys Earth Planet Inter. 2004;143:433-43.

Smith D, Zuber M, Phillips R, Hauck SA, Lemoine F, Mazarico E, et al. Gravity field and internal structure of Mercury from MESSENGER. Science. 2012;336:214-7.

Sohl F, Spohn T. The interior structure of Mars: Implications from SNC meteorites. J Geophys Res. 1997;102:1613-1635.Sohl F, Spohn T, Breuer D, Nagel K. Implications from Galileo observations of the interior structure and chemistry of the Galilean satellites. Icarus. 2002;157:104-19.SohI F, Schubert G. Interior structure, composition, and mineralogy of the terrestrial planets. In: Spohn T, Schubert G, editors. Treatise on Geophysics, vol. 10, Oxford: Elsevier; 2007. p. 27-68.

Sohl F, Schubert G, Spohn T. Geophysical constraints on the composition and structure of the Martian interior. J Geophys Res. 2005. doi:10.1029/ 2005JE002520.Solomon SC. Some aspects of core formation in Mercury. Icarus. 1976;28:509-21.

Solomon CS, Aharonson O, Aurnou JM, Banerdt WB, Carr MH, Dombard AJ, et al. New perspectives on ancient Mars. Science. 2005;307:1214-20.

Spohn T, Sohl F, Breuer D. Mars. Astron Astrophys Rev. 1998:8:181-235.

Spohn T, Acuña MA, Breuer D, Golombek M, Greeley R, Halliday A, et al. Geophysical constraints on the evolution of Mars. Space Sci Rev. 2001;96:231-62.

Stacey FD, Anderson OL. Electrical and thermal conductivities of Fe-Ni-Si alloy under core conditions. Phys Earth Planet Inter. 2001;124:153-62.

Stanley S, Bloxham J, Hutchinson WE, Zuber MT. Thin shell dynamo models consistent with Mercury's weak observed magnetic field. Earth Planet Sci Lett. 2005:234:27-38.

Stanley S, Elkins-Tanton L, Zuber MT, Parmentier EM. Mars' paleomagnetic field as the result of a single-hemisphere dynamo. Science. 2008;321:1822-5.

Stegman DR, Jellinek AM, Zatman SA, Baumgardner JR, Richards MA. An early lunar core dynamo driven by thermochemical mantle convection. Nature. 2003;421:143-6

Stevenson DJ. Turbulent thermal convection in the presence of rotation and a magnetic field: a heuristic theory. Geophys Astrophys Fluid Dyn. 1979;12:139-69.

Stevenson DJ. Mars core and magnetism. Nature. 2001:412:214-9.

Stevenson DJ. Possible connections between the history of the Venus magnetic field and observable features. In: AGU Spring Meeting Abstracts (Vol. 1, p. 08). Am. Geophys. U., Spring Meeting 2002 abstract \#P21A-08. 2002

Stevenson DJ, Spohn T, Schubert G. Magnetism and thermal evolution of the terrestrial planets. Icarus. 1983;54:466-89.

Stewart AJ, Schmidt MW, van Westrenen W, Liebske C. Mars: a new corecrystallization regime. Science. 2007;316:1323-5.

Strom RG, Trask NJ, Guest JE. Tectonism and volcanism on Mercury. J Geophys Res. 1975;80:2478-507.

Suavet C, Weiss BP, Cassata WS, Shuster DL, Gattacceca J, Chan L, et al. Persistence and origin of the lunar core dynamo. Proc Natl Acad Sci U S A. 2013;110:8453-8.

Tian BY, Stanley S, Tikoo SM, Weiss BP. AGU Fall meeting, abstract GP54A-04. 2014.

Tikoo SM, Weiss BP, Buz J, Lima EA, Shea EK, Melo G, et al. Magnetic fidelity of lunar samples and implications for an ancient core dynamo. Earth Planet Sci Lett. 2012:337:93-103.

Tikoo SM, Weiss BP, Cassata WS, Shuster DL, Gattacceca J, Lima EA, et al. Decline of the lunar core dynamo. Earth Planet Sci Lett. 2014:404:89-97.

Tosi N, Grott M, Plesa A-C, Breuer D. Thermo-chemical evolution of Mercury's interior. J Geophys Res. 2013;118:2474-87.

Tsuno K, Ohtani E. Eutectic temperatures and melting relations in the Fe-O-S system at high pressures and temperatures. Phys Chem Min. 2009;36:9-17.

Tsuno K, Frost DJ, Rubie DC. The effects of nickel and sulphur on the coremantle partitioning of oxygen in Earth and Mars. Phys Earth Planet Inter. 2011;185:1-12

Urakawa S, Kato M, Kumazawa M. Experimental study of the phase relation in the system Fe-Ni-O-S up to $15 \mathrm{GPa}$. In: Manghnani MH, Syono Y, editors. High-pressure research in mineral physics. Tokyo: Terrapub; 1987. p. 95-111. 
Usselman TM. Experimental approach to the state of the core; Part I, The liquidus relations of the Fe-rich portion of the Fe-Ni-S system from 30 to $100 \mathrm{~kb}$. Am J Sci. 1975;275:278-90

Vilim R, Stanley S, Hauck SA. Iron snow zones as a mechanism for generating Mercury's weak observed magnetic field. J Geophys Res. 2010;115:E11003. doi:10.1029/2009JE003528.

Weber RC, Lin PY, Garnero EJ, Williams Q, Lognonne P. Seismic detection of the lunar core. Science. 2011;331:309-12.

Weider SZ, Nittler LR, Starr RD, McCoy TJ, Stockstill-Cahill KR, Byrne PK, et al. Chemical heterogeneity on Mercury's surface revealed by the MESSENGER XRay Spectrometer. J Geophys Res. 2012. doi:10.1029/2012JE004153.

Weiss BP, Tikoo SM. The lunar dynamo. Science. 2014;346:1246753. doi:10.1126/science.1246753.

Wicht J, Heyner D. Mercury's magnetic field in the messenger era. In: Shuanggen J, editor. Planetray geodesy and remote sensing. London: CRC Press; 2014

Wicht J, Mandea M, Takahashi F, Christensen UR, Matushima M, Langalis B. The origin of Mercury's internal magnetic field. Space Sci Rev. 2007;12:261-90.

Wieczorek MA, Jolliff BL, Khan A, Pritchard ME, Weiss BP, Williams JG, et al. The constitution and structure of the lunar interior. In: Joliff BL, Wieczorek MA, Shearer CK, Neal CR (eds) New Views of the Moon. Rev Min Geochem. 2006:60:221-364

Wienbruch U, Spohn T. A self-sustained magnetic field on lo? Planet Space Sci. 1995:43:1045-57.

Williams Q. Bottom-up versus top-down solidification of the cores of small solar system bodies: constraints on paradoxical cores. Earth Planet Sci Lett. 2009;284:564-9.

Williams JG, Boggs DH. Tides on the Moon: theory and determination of dissipation. J Geophys Res. 2015;120:689-724.

Williams JG, Nimmo F. Thermal evolution of the Martian core: implications for an early dynamo. Geology. 2004;32:97-100.

Williams JG, Boggs DH, Yoder CF, Ratcliff JT, Dickey JO. Lunar rotational dissipation in solid body and molten core. J Geophys Res. 2001;106:27933-68

Zhan X, Schubert G. Powering Ganymede's dynamo. J Geophys Res. 2012;117:E08011. doi:10.1029/2012JE004052.

Zhang N, Parmentier EM, Liang Y. Effects of lunar cumulate mantle overturn and megaregolith on the expansion and contraction history of the Moon. Geophys Res Lett. 2013:40:5019-23.

Zhang P, Cohen RE, Haule K. Effects of electron correlations on transport properties of iron at Earth's core conditions. Nature. 2015;517:605-7.

\section{Submit your manuscript to a SpringerOpen ${ }^{\circ}$ journal and benefit from:}

- Convenient online submission

- Rigorous peer review

- Immediate publication on acceptance

- Open access: articles freely available online

- High visibility within the field

- Retaining the copyright to your article

Submit your next manuscript at $>$ springeropen.com 